\title{
Comunicación para la inclusión en lo público. Articulación de iniciativas entre comunidades multiétnicas y pluriculturales. Amazonas, Colombia
}

\author{
Sonia Uruburu Gilède*, Álvaro Diego Herrera Arango**, \\ Johanna Marcela Rodríguez Caballero**
}

Recibido: 28 de octubre de 2009 Revisado: 11 de diciembre de 2009 Aprobado: 15 de abril de 2010

\section{RESUMEN}

Este artículo presenta el desarrollo metodológico y los principales resultados y reflexiones del proyecto "Comunicación para la inclusión en lo público: articulación de iniciativas entre comunidades multiétnicas y pluriculturales", realizado por la Facultad de Comunicación Social Para la Paz de la Universidad Santo Tomás desde el año 2008 hasta el 2009 en Leticia, Amazonas. Esta es una experiencia investigativa que propone una discusión en torno a la comunicación y al desarrollo a partir de la comprensión y dinamización de diferentes procesos de desarrollo, realizados en la zona suburbana de Leticia, capital del departamento del Amazonas, Colombia.

\section{Palabras clave}

Comunicación, multiculturalidad, identidad, inclusión en lo público, capital sinergético, empoderamiento

Antropóloga, Magíster en Historia, Magíster en Sociología, D octorada en Antropología, Escuela de Altos estudios Sociales de París, Francia, Docente-investigadora. Coordinadora Comité de Investigación Facultad de Comunicación Social para la Paz, Universidad santo Tomás, Bogotá, Colombia. Dirección electrónica: suruburu@ gmail.com.

** Comunicador Social y Periodista egresado de la Universidad de Antioquia. Magíster en Comunicación egresado de la Pontificia Universidad Javeriana. Investigador y docente en temas como: comunicación y desarrollo, esfera pública, comunicación para el cambio social. Estudiante de D octorado en Comunicación en la Universidad de Montreal (Montreal - Canadá). Dirección electrónica: alvaroherrera0313@ yahoo.com.

${ }^{* * *}$ Comunicadora Social con énfasis en Comunicación y Educación. Universidad Santo Tomás, Bogotá. Dirección electrónica: hallazgos@ usantotomas.edu.co. 


\title{
Communication for Inclusion in public. Articulation of initiatives between ethnic and multicultural communities. Amazonas, Colombia
}

\author{
Sonia Uruburu Gilede, Álvaro Diego Herrera Arango, \\ Johanna Marcela Rodríguez Caballero.
}

\begin{abstract}
This paper describes the methodology and the main results and reflections of the project "Communication for Inclusion in the Public: Articulation of Initiatives between multiethnic and multicultural communities" by the Faculty of Social Communication for Peace of St. Thomas University since 2008 to 2009 in Leticia Amazonas. This is a research experience which proposes a discussion on communication and development based on understanding and dynamic development of different processes carried out in the suburban area of Leticia, the capital of the Amazonas Department, Colombia.
\end{abstract}

\section{Key words}

Communication, multiculturalism, identity, inclusion in the public, synergistic capital, empowerment. 


\section{INTRODUCCIÓN}

Este artículo presenta una experiencia en el campo de la comunicación y el desarrollo en relación con la diversidad étnica desde un enfoque horizontal y participativo, que busca la construcción de tejido social y esfera pública a partir del reconocimiento de un país multicultural, diverso y conflictivo en donde la comunicación se asume como acto humano edificador de redes y relaciones sociales, espacios de encuentro, diálogo y consenso. Esta experiencia se enmarca dentro del proyecto investigativo: "Comunicación para la inclusión en lo público: articulación de iniciativas entre comunidades multiétnicas y pluriculturales", que se realizó desde el año 2008 hasta el 2009.

“Comunicación para la inclusión en lo público..." surgió de un grupo interdisciplinario de comunicadores sociales y antropólogos de la Facultad de Comunicación Social para la Paz de la Universidad Santo Tomás de Bogotá. Tres profesores y dos estudiantes practicantes: los autores de este artículo, y la profesora Marcela Rodríguez y el comunicador social Diego Cortés quienes participaron durante el trabajo de campo. El proyecto está inscrito en la línea de investigación Comunicación y ciudadanía, de la Facultad, y se desarrolló en convenio con la Universidad Nacional de Colombia, sede Amazonia.

Esta investigación plantea describir y analizar estrategias y procesos de comunicación orientados al desarrollo y al cambio social entre comunidades pluriétnicas y multiculturales del Trapecio Amazónico, en la zona suburbana de Leticia, capital del departamento del Amazonas, Colombia, identifi- cando las diferentes iniciativas, espacios, canales de comunicación, tácticas y acciones que hacen posible la generación de un capital sinergético. De esta forma, propone generar espacios que permitan articular esfuerzos aislados en comunicación y desarrollo marcados por la rivalidad, hibridación y diferenciación de las múltiples identidades que conviven en este territorio.

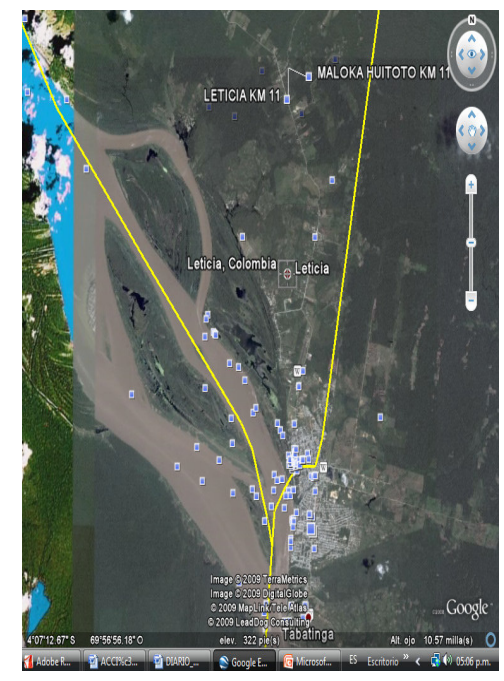

Figura 1. Mapa de la frontera de Colombia.2009, marzo. Tomado de: Google Earth.

El municipio de Leticia se localiza en el extremo suroriental de nuestro país. Se ubica en la región amazónica y su cabecera municipal adquiere una importancia geo-estratégica, porque se localiza sobre el río Amazonas sobre un territorio de frontera política con Brasil y Perú. Allí confluyen pobladores de múltiples orígenes, sobresaliendo las etnias Ticuna, Cocama, Yagua y Uitoto, que interactúan constantemente con los "blancos o mestizos" de la región. Las características fronterizas y la riqueza cultural hacen que este espacio geográfico se transforme en un escenario propicio para el diálogo e intercambio cultural. 
El proyecto tuvo como propósito comprender y construir, junto con los grupos multiétnicos y pluriculturales, propuestas de comunicación que contribuyeran a la participación, gestión, visibilización e inclusión de los actores sociales como sujetos públicos. Se partió del interrogante central: ¿Cómo construir, con las comunidades, estrategias comunicativas interculturales que permitan la articulación y cohesión de iniciativas de comunicación para aportar a un desarrollo comunitario sinergético? Con esto pretendimos generar espacios de diálogo de saberes en donde lo académico interactuara y partiera de la realidad, descentralizando la acción de la comunicación.

Por ello, el proyecto se basó en el reconocimiento de las diversas realidades, experiencias e historias, de la cotidianidad, del sentir, dirigiendo la reflexión a la creación de procesos de inclusión y de reconocimiento al "otro". Se partió de las visiones propias y de los contextos específicos para que desde estos se generaran posibilidades de gestión y articulación de iniciativas que aportaran un desarrollo propio.

El trabajo se llevó a cabo con cuatro grupos poblacionales que habitan en la zona, cada uno perteneciente a una etnia diferente, de manera que pudiera permitirse un diálogo pluricultural y multiétnico de acuerdo con el propósito del proyecto. En este sentido trabajamos con la comunidad Uitoto Nimaira Naimeki Ibiri, que se ubica en el kilómetro 11 de la carretera que comunica a Leticia con Tarapacá; con la comunidad Ticuna de San Sebastián de los Lagos; con el Internado Indígena San Juan Bosco, cuyos estudiantes pertenecen a diversas etnias provenientes de toda la región amazónica, y con la Junta de Acción Comunal del barrio La Nueva Esperanza,
Leticia-Colombia, queriendo involucrar a la población mestiza de la zona de estudio.

\section{Contexto actual de las COMUNIDADES}

Según nuestra narración, lo que se dice ticunas, los yaguas, cocamas, ellos son de aquí mismo, especialmente son de aquí, que habitaban al borde del Amazonas, y allí donde nosotros fuimos, allá comenzando por curripaco, tucanos, carijona, yucuna, miraña, bora, andoque, muinane y murui, fuimos por allá... cogió la ramita de ese árbol y así fuimos quedando... Fuimos comiendo lombrices, esa yuca grande hasta encontrar el árbol, así nos contaron nuestros antepasados. Entonces nosotros estamos otra vez acá para soltar este amarre que nos está haciendo sufrir a nosotros (Muinane Marcelo, 2008, 19 de septiembre, relato oral. Mito de Monillamena, abuelo uitoto.rtf - 28: (6:9)).

Antes de emprender el recorrido y las reflexiones que se tejieron en este trabajo es necesario dedicar un espacio para conocer brevemente el contexto actual de las comunidades que participaron en el proyecto, para así comprender la multiculturalidad y la contante movilidad de los actores sociales de esta zona.

\section{Los Ticuna de San Sebastián de}

\section{Los Lagos}

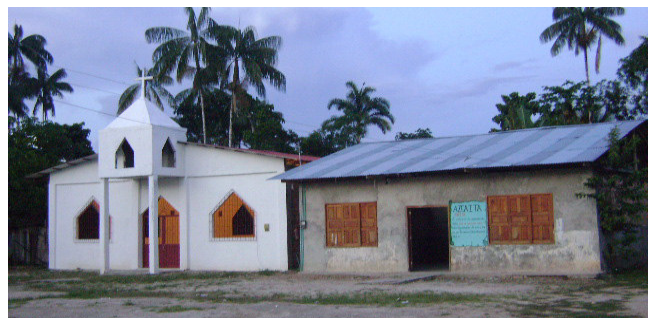

Figura 2. Espacios de encuentro. Iglesia y salón comunal de la comunidad San Sebastián de los Lagos, 2008, 10 de julio. Fotografía tomada por: Herrera Arango, A. 
En Colombia los Ticuna son uno de los grupos etnolingüísticos más numerosos de la Amazonia, teniendo en cuenta su territorio y número de población. Actualmente, alcanzan una población aproximada de 7.890 en Colombia, 1.787 en el Perú y 25.737 en el Brasil (Lasprilla, 2009: 22). Se ubican al sur de la Amazonia en el río Cotuhé, Caño Ventura, Santa Lucía, Buenos Aires y en la zona de influencia de Leticia. Se asientan en los resguardos de San Antonio de los Lagos, San Sebastián, El Vergel, Macedonia, Mocagua y Cotué-Putumayo, en el departamento del Amazonas (Fajardo y Torres, 1987).

En 1982 se constituyó el resguardo de San Antonio y San Sebastián de Los Lagos, con una extensión de 237 hectáreas, dividido en dos parcialidades, cada una con 189 y 48 hectáreas, en su orden. La comunidad de San Sebastián de Los Lagos se encuentra en el sector rural de expansión urbana al noroccidente de la ciudad de Leticia, en la ribera de la quebrada Yahuarcaca, afluente del río Amazonas en el kilómetro 5 de la carretera vía Los Lagos, del municipio de Leticia (Reyes, 2009: 25). Actualmente tiene 127 familias y 528 habitantes.

La cercanía al casco urbano de Leticia ha generado nuevas dinámicas productivas, sociales y políticas a través del trabajo asalariado, servicios de salud y las intervenciones institucionales. Esto se evidencia en algunos relatos de Ruth Fernández, líder de la comunidad de San Sebastián:

... la pérdida de fauna, flora, la riqueza de la selva, los yacimientos, la pérdida de eso. La vivienda cambia, hoy en día ya se ve que la mayoría tiene vivienda de materiales. Yo me acuerdo que yo a los 8 años, nosotros todavía teníamos hoja de caraná, hoy en día es muy diferente; la alimentación también, ejemplo los animales como la danta, el borugo también se ha perdido, lo que es la carne de monte es muy escasa acá (...).

Los ruidos, esos cambios que aquí entran, mucho rechazo, los niños ya no tienen ese conocimiento, se burlan de nuestros abuelos, no les gusta participar, se burlan" (Lorenzo Fernández, 2008, 1 y 3 de octubre, entrevista).

En estos relatos Ruth afirma que la cercanía a Leticia genera cambios en la infraestructura, lo cual, a la vez, transforma las tradiciones y las formas de organización, de reconocimiento y concepción de la cultura.

En la comunidad sobresalen algunas problemáticas, como el incremento poblacional y la escasez de tierras cultivables debido a la división continua de las antiguas chagras o parcelas, lo que genera dificultades en el acceso a recursos de sustento y alimentación. Por esto muchos de sus habitantes buscan fuentes de trabajo externas, en el casco urbano, lo que genera procesos de aculturación acelerados. Tristemente, una de las fuentes de ingreso en la actualidad es el botadero a campo abierto de residuos sólidos del municipio de Leticia. Este se ubica cerca a la comunidad y se convirtió en escenario donde algunos de los indígenas del resguardo cambian sus opciones económicas tradicionales por el reciclaje, en busca de recursos monetarios.

Asimismo, estas nuevas relaciones de trabajo, nuevas dinámicas en las relaciones de autoridad y reconocimiento del saber tradicional, se observan con mayor frecuencia entre los jóvenes, como lo evidencia el siguiente fragmento de una entrevista:

Los jóvenes no participan, no entienden, no van a la reunión... La pelazón 
muy poco se hace, no veo que se haga nada, ni mingas ya no hacen, ni nada; al comienzo sí se hacían mingas, lo que es la minga que trabajaran todos cuando había presidente de la junta se organizaba, falta una organización, un comité. Desde el noventa no se hace, hoy ya no veo nada de eso (Coelho Pinto, 2008, 12 de septiembre, entrevista, p. 1).

Frente a esta falta de apropiación identitaria de los jóvenes se están perdiendo los espacios tradicionales de aprendizaje entre aquellos y los abuelos, esos encuentros que permiten revivir de manera permanente la historia ticuna, lo cual despierta grandes preocupaciones entre las personas de la comunidad: “... los saberes de la abuelas se están perdiendo y le podrían servir a la comunidad, podríamos mirar como ese punto de las abuelas" (Acercamiento San Sebastián de Los Lagos, 2008, 7 de julio, diario de campo).

Este panorama general de los principales problemas de esta comunidad deja ver la complejidad cultural, social y económica que producen su recorrido histórico y ubicación geográfica específica, obligando a la población a proponer nuevas lógicas de supervivencia.

\section{Comunidad Uitoto'- del Km 11- Nimaira Naimeki tbirì (Patio de la Ciencia Dulce)}

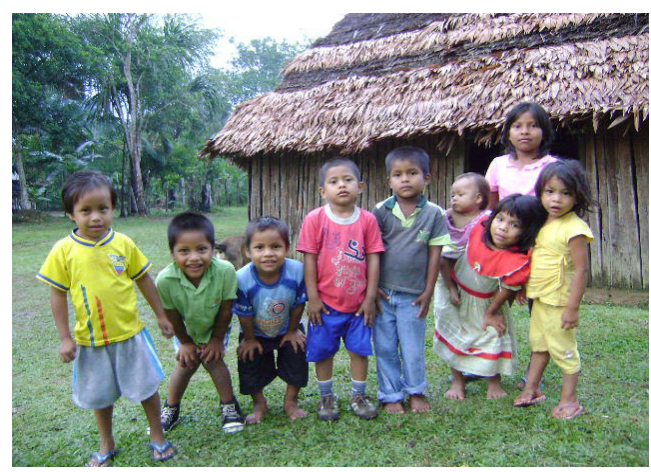

Figura 3. Los niños también son unos sabedores de su cultura. Participantes de los talleres en comunidad de km 11, 2008, diciembre. Fotografía tomada por: Herrera.

Los indígenas fundadores del resguardo de los kilómetros 6 al 11 -que hoy se han dividido y formaron así el resto de comunidades: Ciudad Jitoma ( $\mathrm{km} 7$ ), Monillamena (km 9), Casillanaira o Multiétnico (km 9,5)provienen en su mayoría la zona de Pebas, Perú, lugar en donde se establecieron después de ser desplazados a la fuerza por diversas empresas extractivas del caucho a principios del siglo XX. Los uitoto son originarios de la Chorrera y de las zonas interfluviales de los departamentos de Caquetá y Putumayo (Azcaita, 2002). Muchas de las personas que se reclutaron como mano de obra, desplazadas de sus territorios y que lograron sobrevivir al régimen, comenzaron su retorno desde los distintos campamentos hacia sus lugares de origen. Algunos, solos o en

En la zona de estudio se denomina como uitoto a los indigenas provenientes de la región del bajo Caquetá-Putumayo. Realmente pertenecen a diversas etnias con diferente lengua, pero con una organización social similar. Utioto, Ocaina, Nonuya-Uitoto, Bora, Miraña, Andoque, Muinane y Resigero (Pineda, 1993: 47). En los kilómetros 7 y 11 de la carretera Tarapacá - Leticia se establecieron indigenas descendientes de estas etnias. 
compañía, comenzaron a buscar el camino de vuelta en búsqueda de sus familiares y terminaron estableciéndose en la zona suburbana de Leticia conocida como los kilómetros. Allí lograron reunirse, refundarse y recrear sus tradiciones en un esfuerzo de sobrevivencia cultural. El siguiente relato de una habitante de la comunidad expone su origen de acuerdo con los diferentes desplazamientos hasta llegar a la comunidad actual.

Yo soy del Perú, pero mi papá, de Chorrera; él es del Caquetá con mi abuelito, netamente de allá ellos vinieron, después ellos se regaron, se urbanizó, pero la gente que son de acá venimos es de allá, pero todos somos uitotos que vinieron de por allá y se regaron; entonces un poco quedaron allá, otros vinieron aquí, vinieron de allá otros se quedaron (Rodríguez, Rosalía, 2008, 29 de octubre, entrevista, km11_entrevista_rosalia.rtf - 9:17 (54:54)).

El resguardo fue constituido mediante resolución del Incora No. 005 de 1986 con una extensión de 7.560 hectáreas; en un comienzo las cuatro comunidades reconocidas (hay dos que no lo han sido: el Multiétnico y Casilla Naira) que en la actualidad conforman el resguardo estaban articuladas bajo una sola organizaión, manejada por dos parcialidades, la del kilómetro 6 San José con población en su mayoría ticuna, y los uitotos, que centraban su organización en el kilómetro 11.

La comunidad Uitoto del km 11 se fundó el 2 de abril de 1962 bajo la figura de junta de acción comunal. La constitución de esta junta llegó acompañada de la creación de las reservas indígenas donde la propiedad le pertenece al Estado, pero el usufructo pertenece a los indígenas (Nieto, 2006:57).
Entre las grandes preocupaciones en el interior de la comunidad se encuentra la pérdida de identidad cultural de los jóvenes y el desinterés hacia los saberes tradicionales que, al igual que como sucede en San Sebastián de Los Lagos, se genera por la cercanía a Leticia y la intervención institucional. Así lo describe el gobernador del cabildo:

El colegio genera cambios en los jóvenes, los jóvenes que van a la ciudad, a los 6 meses ya no pueden ir a la chagra (zona de cultivo), y la tecnología, la moda, consumismos, comienzan a dominar. La nuevas generaciones niegan su esencia (Acercamiento km 11, 2008 , 7 de julio, diario de campo).

Asimismo, un joven de la comunidad describe los diferentes cambios que se generan en los jóvenes, haciendo énfasis en la falta de espacios de diálogo para reafirmar la esencia cultural:

... todo el intercambio cultural ya que vivimos con dos contrastes, Brasil y Perú, la globalización, lo que es la informática, el Internet y todo eso, yo creo que eso ha sido entre comillas las dificultades de los jóvenes, que se apoyan más en la informática, la parte científica, los conocimientos occidentales, y como que no se apartan si no que no hay esos espacios donde los jóvenes puedan aprender a conocer sus virtudes, creo que esa ha sido la dificultad más grande.

... Inclusive en nuestra comunidad no hay como ese espacio que se les brinda a los niños, los jóvenes, la oportunidad de reunirse, entre un anciano, un joven, los niños, los padres de familia donde se compartan cuentos, leyendas, porque otra dificultad que yo he visto es que los ancianos son como muy reservados en esos conocimientos, digamos, se enseña una canción, les explican digamos lo básico, pero no lo fundamentan, que uno verdaderamente aprenda 
eso y lo aplique; yo he notado que son muy reservados con esos conocimientos. El conocimiento de nuestra cultura va de herencias, digamos familiar, digamos la familia Flores, todo eso, todo ello el abuelo le trasmite al nieto, el nieto tiene sus hijos y le transmite ese conocimiento. Entonces sigue siendo así esa cadena de conocimientos en la misma familia (Esbar Peyes, 2008, 25 de octubre, entrevista).

\section{Barrio La Nueva Esperanza ${ }^{2}$}

El barrio se fundó en 1996; los primeros fundadores fueron un señor de nombre Capinoa y los hermanos Ipuchima. Este barrio venía de una reubicación de zona de riesgo. Había unas plantas de energía, la gente estaba viviendo en ese lugar, pero era de alto riesgo, peligroso, empezando por el ruido; es un sector donde también pasa un caño y por el otro lado el ruido de las plantas, y se iba desmoronando también el terreno. Se optó por reubicar a la gente, una parte del barrio (la de allá), esta parte fue por convención colectiva de los trabajadores que éramos en ese entonces municipio, por un sindicato, y se hizo por convención colectiva de trabajadores y a cada trabajador se le dio un terreno para que pudiera ubicar su familia. Así ha ido creciendo el barrio, pero esa fue la forma de poder reubicar el barrio acá, fue un trueque del municipio que hizo con los Fajardo. Los Fajardo le cedían al municipio estas tierras y el municipio los exoneraba de unos impuestos de predial. El municipio los exoneró y les legalizó sus tierras y les pagó con terreno (Encuentro con los miembros de la Junta de Acciòn Comunal del barrio La Nueva Esperanza, Leticia, julio de 2008).

2 Este texto se construyó a partir de la entrevista a Hernando Mosquera, presidente JAC del barrio La Nueva Esperanza el 12 de Agosto de 2008, y a partir de los diferentes diálogos que se dieron con habitantes del barrio.
Desde su reubicación, el barrio fue bautizado como La Nueva Esperanza. Este se caracteriza por el origen multicultural de sus habitantes, ya que en él conviven colombianos de diversas regiones del país, una gran cantidad de peruanos, algunos brasileros y personas de las diferentes etnias indígenas de los alrededores de Leticia.

En cuanto a las problemáticas sobresalientes, en el barrio se encuentra la contaminación ambiental, pues su ubicación cerca al caño Calderón y la falta de conciencia ambiental de algunos de sus habitantes ha provocado la contaminación de este humedal, generando problemas de salud y a su vez conflictos entre los vecinos:

El problema de contaminación ha generado problemas de salud en los niños del barrio, ya que estos juegan en el caño descalzos, pisando todo tipo de desechos y materia fecal que sale de las tuberías provisionales que construye la gente en sus casas, porque este sector, por ser de reubicación reciente, no posee un alcantarillado. Además de esto, los padres de los niños no están pendientes de lo que ellos hacen y no se preocupan por las consecuencias que trae dejar que los niños jueguen en esta zona. Por otro lado, las personas que viven en estas casas arrojan las basuras al caño, obstruyendo el camino del mismo y produciendo el represamiento de aguas negras, que generan mal olor y atraen muchos insectos y roedores (Acercamiento barrio La Nueva Esperanza, 2008, 17 de julio, diario de campo).

Esta situación genera que los conflictos entre los habitantes del barrio se den de manera más frecuente, puesto que entre disgustos, rumores y la falta de una conciencia colectiva surge un clima de convivencia totalmente fragmentado, en el que se pierde el 
sentido de lo comunitario y se diluye el papel de la comunicación como mediadora de conflicto. Decir que los peruanos son "cochinos", poco participativos o los causantes de diversos problemas en el barrio, nos describe las desigualdades, los imaginarios y los conflictos sociales que surgen por los estereotipos etnocéntricos. El otro, por lo general desconocido, extraño y concebido como inferior, se considera el causante de los problemas de la comunidad, que no reconoce su propia corresponsabilidad.

\section{Institución Indígena San Juan Bosco}

Esta institución escolar de carácter multiétnico se ubica en el km 2, carretera vía Leticia - Los Lagos. Fue fundada en 1976 por el monseñor Marcelino Eduardo Canyes Santacana. Inicialmente, era una escuela de básica primaria. Luego, debido a las necesidades regionales en materia de educación, se transformó en un centro pedagógico de educación básica secundaria y media vocacional con características de internado masculino.

Actualmente, cuenta con 850 estudiantes provenientes de diferentes comunidades y corregimientos del Amazonas, como: La Pedrera, Mirití, Araracuara, Tarapacá, Puerto Arica, La Chorrera y otras comunidades del municipio de Leticia y Puerto Nariño, lo que demuestra su diversidad cultural. En él conviven e interactúan diferentes grupos étnicos como: Ticunas, Uitotos, Matapíes, Yucunas, Mirañas, Cubeos y mestizos.

Con base en estas características culturales, el colegio adelanta el Proyecto para el desarrollo intercultural de los pueblos amazonenses, que tiene como objetivo propiciar espacios de participación entre los estudiantes para fortalecer la capacidad liderazgo. Para ello recurre a estamentos de participación, como los consejos estudiantil y de convivencia, el gobierno estudiantil y el comité de democracia. Todo esto regulado a través de los estatutos de partido político y la cartilla didáctica de estamento de participación.

Temas como política, participación, liderazgo y cultura desde una perspectiva indígena es una de las grandes apuestas del colegio. Lamentablemente, al final todo termina en que "debemos prepararnos para la globalización y tecnificar la chagra" (Vi1la Saady, 2008, julio 9, diario de campo), es decir, todavía no se asume la cosmovisión indígena, y toda propuesta se reduce a una inclusión económica y productiva. A la vez, el gobierno escolar, aunque permite establecer procesos de participación, es tan solo una pequeña réplica de las dinámicas participativas del Estado, de un estado occidental que aún sigue siendo impuesto.

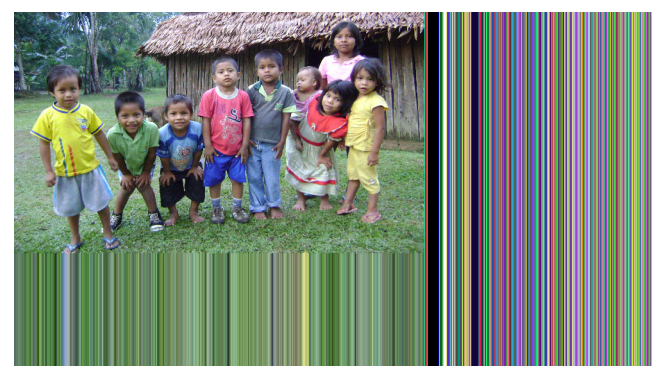

Figura 4. Jóvenes explorando la radio. Taller con los jóvenes de la Institución Indígena San Juán Bosco. 2008, septiembre. Fotografía tomada por: Rodríguez Caballero, J.

Por otro lado, a pesar de la diversidad cultural que caracteriza al colegio, predomina la falta de espacios de participación, reconocimiento y diálogo e intercambio cultural, 
lo que se evidencia en el silencio y en la timidez de los jóvenes frente a su origen y su cultura. Entonces, la vergüenza y el miedo a la burla se transforman en sentimientos generalizados que edifican una cultura del olvido entre los jóvenes, pues ellos, sin importar que sea un colegio indígena, temen decir yo soy ticuna, soy uitoto o soy bora. Les da miedo hablar en su dialecto y aún más de su cultura.

\section{RECORRIDO METODOLÓGICO}

La investigación se realizó bajo el enfoque metodológico de la investigación - acción participativa (IAP). De acuerdo con esta perspectiva, las personas son vistas como agentes de cambio que ejercen un papel fundamental y protagónico para la transformación de la realidad social. "La IAP genera conciencia socio-política entre los participantes en el proceso -incluyendo tanto a los investigadores como a los miembros del grupo o comunidad" (Fals Borda, 2003).

La IAP se basa en la participación, reconocimiento, empoderamiento y cooperación entre los actores sociales. Además, busca contribuir, a través de procesos de comunicación, a la formación de "sujetos de saber y de poder, sujetos sociales críticos, reflexivos y conscientes de su capacidad constructiva y transformadora" (Torres, 2003: 13). Las rutas que se edificaron durante este proceso fueron lideradas por las comunidades que participaron, quienes plantearon sus necesidades, intereses, espacios y tiempos. Nuestro papel se centró en la canalización y dinamización de dichos intereses.

Durante el trabajo de campo obtuvimos una experiencia, en conjunto con las comunidades, de construcción y reconstrucción de conocimiento, en donde logramos generar espacios de diálogo, reflexión y producción de sentido entre las comunidades Uitoto de kilómetro 11 vía Tarapacá; los Ticuna, en San Sebastián de Los Lagos; el Internado San Juan Bosco, y el barrio La Nueva Esperanza. De este modo, las actividades planeadas con y para las comunidades se orientaron hacia la búsqueda del entendimiento compartido y hacia la construcción o visibilización de sentidos comunes.

Inicialmente definimos los ejes temáticos a partir de los cuales centramos las acciones durante el trabajo de campo. Estos surgieron de los mismos recorridos, diálogos y encuentros que dejaron ver las necesidades, posibilidades y recursos de cada comunidad. De tal forma, la investigación giró en torno a las siguientes categorías:

\section{Identidad \\ 2. Liderazgo \\ 3. Construcción de lo público \\ 4. Gestión del desarrollo}

Estas hicieron posible la identificación de puntos en común y el reconocimiento de las propuestas de cada comunidad. Con base en ellas se fortalecieron las iniciativas y las estrategias comunicativas, tanto formales como informales, enfocadas a la generación de espacios de diálogo, de saberes, de reconocimiento y de intercambio cultural.

Este diálogo de saberes inició desde el mismo momento en que realizamos el primer acercamiento a las comunidades por medio de la generación de acuerdos y negociaciones, donde establecimos en conjunto los objetivos específicos y la forma en que se articularían al propósito general del proyecto. 


\section{Definición de Objetivos}

\section{Comunidad Nimaira Naimeki Ibiri (co- munidad Uitoto del $\mathrm{km} \mathrm{11)}$}

Propiciar la visibilización ante la comunidad de las diferentes percepciones que los niños tienen de ella, las problemáticas que allí se viven, los diferentes elementos identitarios, espacios y conocimiento tradicional, para así contribuir en el reconocimiento de los niños como miembros activos de la comunidad.

\section{Comunidad Ticuna de San Sebastián de Los Lagos}

Contribuir a un re-conocimiento identitario y cultural de la comunidad, que fortalezca el liderazgo y el empoderamiento hacia la gestión de proyectos comunitarios.

Internado San Juan Bosco, colegio indígena pluriétnico

Fortalecer el liderazgo, la autogestión y el reconocimiento de la diversidad cultural, a partir de la construcción de productos y estrategias en comunicación y educación.

\section{Junta de Acción Comunal del barrio La Nueva Esperanza, Leticia, Colombia}

Generar procesos de formación a líderes multiplicadores en el barrio La Nueva Esperanza en torno a la gestión de proyectos y mediación de conflictos, específicamente en el diseño de estrategias comunicativas correspondientes a la problemática del humedal Calderón.

\section{Desarrollo metodológico}

\section{Fase I: diagnóstica}

Durante esta fase realizamos un primer acercamiento a las comunidades participantes en el proyecto, a sus líderes y organizaciones, para identificar sus intereses, necesidades y experiencias en materia de comunicación.

Con base en este proceso, definimos las líneas temáticas para abordar con cada comunidad: identidad con la comunidad de San Sebastián de Los Lagos, enfocada al grupo de las abuelas; derechos y deberes con la comunidad del kilómetro 11, enfocada en el grupo de niños y jóvenes; liderazgo y comunicación con los estudiantes de $10 \mathrm{y}$ 11 grado del Internado Indígena San Juan Bosco, y gestión del desarrollo con líderes del barrio Nueva Esperanza de Leticia. A partir de allí, realizamos los acuerdos conjuntos entre comunidades e investigadores para desarrollar el proyecto en las condiciones propuestas por los grupos de trabajo.

\section{Fase II: acción participativa}

Aquí adelantamos una exploración general de los diferentes proyectos de comunicación y desarrollo implementados (proyectos productivos, planes de desarrollo, planes de vida, investigaciones académicas). Realizamos reuniones de acercamiento general a las comunidades, lo cual permitió consolidar procesos como:

- Mapeo de autoridades regionales y comunitarias (cabildos indígenas, miembros de JAC, líderes comunitarios, instituciones indígenas). 
- Reconocimiento de los participantes a través de la elaboración de un diagnóstico de la situación actual de la comunidades con la cuales se trabajó.

Con base en lo anterior, definimos y delimitamos las acciones que se debían emprender y formulamos un plan de trabajo inicial que contemplara el diseño de técnicas de investigación que respetaran los intereses y propuestas de la comunidad.

Este trabajo fue el punto de partida para iniciar el proceso de acción y reflexión liderado por las comunidades, a través de estrategias de participación como talleres, diálogos de saberes, encuentros planteados por las mismas personas de la comunidad, grupos de discusión, encuentros lúdicos, observación participante $u$ otras acciones que nos permitieron la construcción de vínculos y el cumplimiento de los objetivos planteados.

Dichas búsquedas se generaron de manera más explícita en espacios como los talleres, ya que facilitaron el intercambio de ideas y la generación de vínculos de cooperación, a través de un diálogo que, más allá de lo verbal, recurrió a recursos como el dibujo, la realización de artesanías, los bailes y los juegos.

Fase III: Sistematización de la información y redacción del informe de investigación

Finalmente, durante la fase de sistematización creamos categorías de análisis de los datos recogidos en el trabajo de campo, agrupadas según los ejes temáticos de la investigación. Estas permitieron profundizar en los temas trabajados en la primera y la segunda fase, identificar las relaciones entre ellos y con los conceptos del marco teórico. A partir de allí surgieron las descripciones y análisis de múltiples realidades en un contexto multicultural, en donde la comunicación surge como hilo conductor y constructor de vínculos e iniciativas propias.

\section{Escenarios de diálogo y reconocimiento}

Todo el proceso investigativo se realizó a través de técnicas participativas que posibilitaron la generación de acuerdos iniciales, la emergencia de nuevas rutas de acción y sobre todo la participación y empoderamiento de las comunidades hacia el proyecto, logrando ellas superar obstáculos comunes que generan la desconfianza y el silencio que se dan por el mismo desconocimiento de los propósitos de los proyectos, del papel de los investigadores y de las mismas comunidades.

Las técnicas de investigación se asumieron como espacios y escenarios que posibilitaron la construcción de vínculos a través de la interacción, el diálogo y la diversidad, es decir, como un diálogo de saberes encaminado al consenso, a la concertación y al reconocimiento de las distintas maneras de ver, sentir, conocer y asumir la realidad.

Las técnicas desarrolladas durante las fases I y II fueron:

- Observación etnográfica con registro en diario de campo

- Entrevistas: abiertas, grupales, diagnósticas, de comprobación, semiestructuradas

- Talleres

- Técnicas interactivas de investigación participativa: mapeo, árbol de problemas 
- Grupos de discusión

- Diálogos de saberes

- Encuentros tanto formales como informales con los participantes en el proyecto

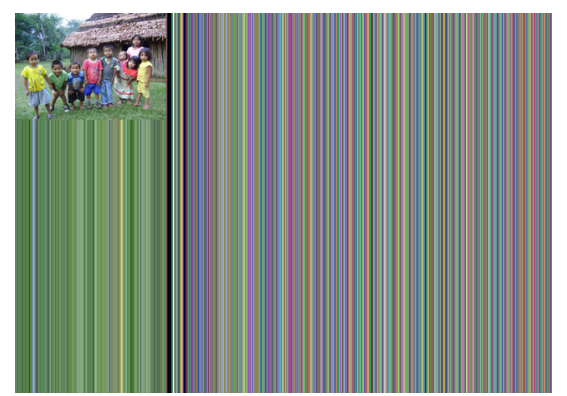

Figura 5. Jóvenes explorando la radio. Taller en el Sena con los jóvenes de la Institución Indígena San Juan Bosco. 2008, 10 de septiembre. Cortés, D.

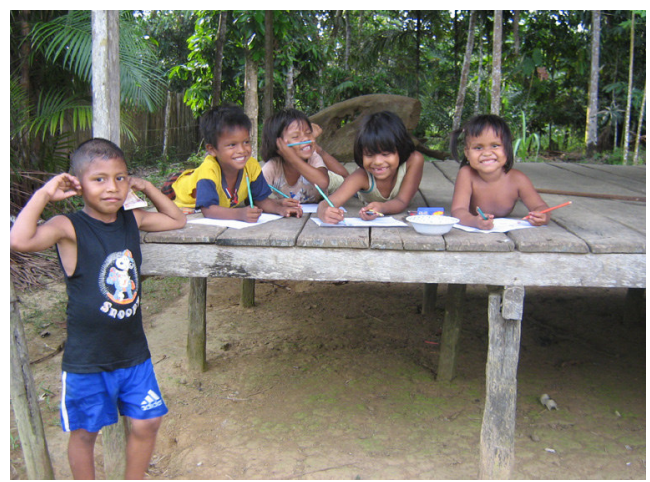

Figura 6. Aprendamos en nuestra maloca. Taller km 11, 2008, septiembre. Rodríguez Caballero, J.

El contacto directo con las comunidades a través de estas técnicas hizo posible una mayor comprensión de las nociones centrales para el proyecto. Entre ellas se encuentran: desarrollo, productividad, territorio, identidad, iniciativas de comunicación, concepción de autoridad, organización social y dinámicas internas que se desarrollan a partir de la cotidianidad. Con base en la importancia que para este proyecto revistió la reflexión y la acción de los participantes, la mayoría de los encuentros con las comunidades participantes se realizaron bajo la técnica del taller, por esto queremos hacer un pequeña reflexión en torno a este espacio a partir de la manera como se desarrollaron.

\section{Talleres}

La propuesta consiste en problematizar las imágenes, ideas, creencias, nociones y construcciones sociales de sentido que, al relacionarse con prácticas, historias, deseos, sentimientos, vivencias y emociones, se constituyen en referentes configurativos de proyectos o escenarios sociales posibles (Ghiso, 2000: 70).

El taller les permite a los participantes constituirse como un colectivo en un espacio público, "Un aquí, un ahora donde se generan nudos de relaciones no solo desde el decir sino desde la interacción (corporal, dramática, gestual y espacial) y desde el hacer" (Alcalá, 2000:147). Desde este planteamiento se desarrollaron los encuentros con las comunidades, en donde la voz de los participantes, sus capacidades y habilidades fueron las que lideraron y orientaron las dinámicas y temáticas de cada taller. Este se constituyó en un espacio que permitió potenciar la diversidad, las reacciones colectivas y los pensamientos en red, generados por los mismos acuerdos y desacuerdos, por el respeto a la palabra y el reconocimiento del otro. De este modo, se estableció, como lo argumenta Guillermo Gutiérrez (2003), una metodología participativa que privilegia la reflexión en torno a los saberes de los participantes.

A su vez, los talleres que se realizaron en las comunidades concordaron con los intereses, posibilidades y recursos de las mismas, en espacios y grupos propios de participación que facilitaron esa construcción de lo público. Es decir, el tiempo y los espacios se establecieron teniendo en cuenta la co- 
tidianidad de los participantes, su tiempo libre y los lugares cotidianos de encuentro y diálogo.

Inicialmente, los talleres tuvieron como objetivos un acercamiento a las comunidades que garantizara reducir la distancia entre el investigador y la población participante, y la emergencia de un discurso individual contrastado con uno colectivo a partir de las dinámicas prácticas de cada taller.

Con base en este proceso, establecimos los días de encuentro, los lugares propicios y los actores que participaron de manera constante, tal como se resume en la siguiente tabla:

Tabla 1. Lugares y actores que participaron en los encuentros

\begin{tabular}{|l|l|l|}
\hline \multicolumn{1}{|c}{ Comunidad } & Grupo poblacional & \multicolumn{1}{c|}{ escenarios } \\
\hline $\begin{array}{l}\text { Comunidad Nimaira Naimeki Ibiri } \\
\text { (patio de ciencia dulce), km 11 }\end{array}$ & niños & $\begin{array}{l}\text { la maloca Escuela Nuestra } \\
\text { Señora de las Mercedes }\end{array}$ \\
\hline San Sebastián de Los Lagos & abuelas & Casa comunitaria \\
\hline $\begin{array}{l}\text { Internado San Juan Bosco, institución } \\
\text { indígena multiétnica }\end{array}$ & jóvenes & Auditorio Sena \\
\hline $\begin{array}{l}\text { Junta de Acción Comunal del barrio La } \\
\text { Nueva Esperanza, Leticia-Colombia }\end{array}$ & líderes & Centro de Salud \\
\hline
\end{tabular}

Los grupos poblacionales con los cuales trabajamos se escogieron con base en la pertinencia del tema, de acuerdo con los intereses expuestos por cada una de las comunidades en la fase diagnóstica. Fueron estos actores los que lideraron los encuentros y motivaron a las demás personas a vincularse a este proceso.

De esta manera, los talleres posibilitaron: primero, la exploración del conocimiento tradicional y local, los referentes identitarios, la reconstrucción de la memoria histórica y la lectura del contexto actual. Segundo, la identificación de los roles, las formas de apropiación de escenarios de participación e inclusión en lo público, además del reconocimiento del sujeto como actor colectivo. Tercero, el fortalecimiento de procesos de liderazgo y los espacios de encuentro y articulación de iniciativas.

\section{Resultados y reflexiones}

En las comunidades indígenas suburbanas, los espacios y prácticas tradicionales, como los rituales, cantos, chagras, mambeaderos y malocas, además de ser manifestaciones culturales, son parte esencial del fortalecimiento de la capacidad de gestión y visibilización en lo público. Por ello, durante el trabajo de campo realizamos una serie de acciones centradas en el reconocimiento de los espacios y formas de comunicación tradicional, además de referentes identitarios, de los juegos, las cerámicas y las artesanías que expresan el pensamiento indígena y se transforman en manifestaciones de lo público.

Asimismo, la reconstrucción del mundo tradicional, sus espacios y saberes, a partir de la recreación de elementos de unión cultural, de dibujos, historias, teatros, recorri- 
dos, encuentros, diálogos, bailes y juegos, nos permitió comprender las formas de asumir, percibir y resignificar la tradición en un contexto multicultural. El valor de los relatos y el contraste de las experiencias individuales y colectivas facilitó la exploración en temas como espacio y el territorio, formas de aprendizaje, relaciones de género, parentesco, roles y poder en escenarios tradicionales. Una serie de dinámicas que se desarrollan en la cotidianidad de las comunidades y dejan ver sus conflictos, organización, pensamiento y el papel de la comunicación.

Por ende, los resultados de este proyecto se tejen a partir de dichas voces, pues son los abuelos, los niños y los jóvenes quienes nos muestran las lecturas de su realidad, expresándonos su visión de desarrollo, propuestas de reconocimiento y de una verdadera inclusión.

El siguiente apartado de este texto tiene como primer objetivo dar a conocer una propuesta de inclusión desde un reconocimiento multicultural. Como segundo visibilizar las percepciones e impactos que han generado, en el interior de las comunidades, los diferentes modelos y formas en que se da el desarrollo desde visiones externas en contraste con iniciativas propias. $Y$ finalmente, el papel y los retos de la comunicación para una verdadera participación y articulación, iniciativas propias donde no se opaque al otro ni se nieguen los saberes propios.

\section{Cultura y MULTICULTURALIDAD}

¿Acaso Puede Hablarse De Una Identidad Multicultural?

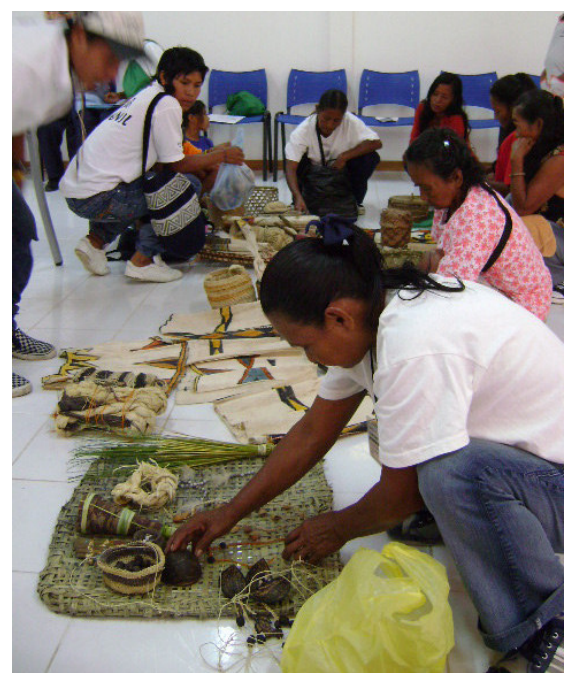

Figura 7. Encuentro. Iglesia y salón comunal de la comunidad San Sebastián de Los Lagos, 2008, 10 de julio. Fotografía tomada por: Herrera Arango, A.

Partimos de la definición de cultura como "el conjunto de rasgos distintivos intelectuales y materiales, intelectuales y afectivos que caracterizan a una sociedad o a un grupo social y que abarca, además de las artes y las letras, los modos de vida, las maneras de vivir juntos, los sistemas de valores, las tradiciones y las creencias" (UNESCO, 2002:3). Esta definición adquiere un grado de complejidad avanzado si tenemos en cuenta la alta diversidad étnica y cultural de la zona de estudio. De hecho, los procesos históricos, la cercanía a la ciudad de Leticia, el vínculo de la población joven con el sistema educativo nacional y la influencia de los medios de comunicación, como la radio y la televisión, han generado un desinterés creciente de los jóvenes hacia la tradición que fundamenta la identidad indígena. 
En el caso de la periferia urbana de Leticia, todavía se puede reconocer culturalmente a los ticuna, pese a su convivencia con cocamas y con yaguas. Asimismo sucede con los uitoto, nombre bajo el cual se reconoce a los habitantes del km 11, aunque realmente pertenecen a las etnias Murui, Muinane, Bora, Ocaina y a una minoría Ticuna y Yagua. Allí, la complejidad de relaciones interétnicas se manifiesta en un conjunto de actividades de renovación y reformulación constante de múltiples expresiones culturales.

La situación de multiculturalidad se hace aún más compleja entre los habitantes del barrio La Nueva Esperanza, de Leticia. Ellos se identifican como mestizos. Son un conjunto de personas que provienen del interior del país o de otras regiones, como el Caquetá, Putumayo e incluso del Chocó, y de los países vecinos, como Perú y Brasil, que conviven con migrantes de las etnias indígenas. La identidad entonces fluctúa entre la propiamente nacional, la étnica y la trifronteriza, en donde cohabitan aspectos culturales de la región de frontera entre Colombia, Perú y Brasil.

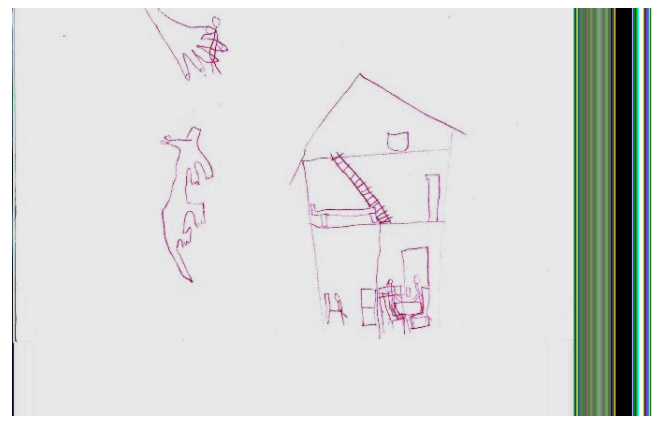

Figura 8. Cumbre de ancianos indígenas, 2008, septiembre. Fotografía tomada por: Rodríguez Caballero, J.

Desde el punto de vista de la identidad, durante el trabajo de campo pudimos observar que los indígenas proponen asumir la multiculturalidad desde la categoría supraétnica de "paisanos". Esta les permite autodefinirse a partir de la diferencia con el "blanco" perteneciente a la sociedad occidental y plantea una identidad que va más allá de la etnia y del territorio. También, surge de experiencias compartidas: un mismo sentimiento resultado del contexto histórico, del contacto y de las alianzas culturales entre diferentes etnias. En ella, se resaltan aspectos como la unión entre las comunidades indígenas como una forma de enfrentar las problemáticas compartidas.

Por ejemplo, en el caso del $\mathrm{km} \mathrm{11}$, aunque la mayoría son uitoto, muchos han realizado alianzas con hombres o mujeres de otras etnias, fundamentalmente ticunas, cocamas o yaguas. Esto demuestra la aceptación del "otro" en un contexto histórico particular y la creación de una categoría general que define al indígena como tal, ajeno a la etnia. Es la categoría de "paisano", que se caracteriza por un sentimiento particular, una visión del mundo similar, una relación con la sociedad nacional, una historia de resistencia, una semejanza global que lo identifica como nativo, como habitante original del territorio. Podría decirse que esta categoría es una forma de construcción de la identidad por oposición al "blanco", es decir, el indígena busca alianzas y formas de identificación con quien no pertenece a la cultura occidental. El siguiente relato da cuenta de la diferencia entre el "blanco" y el "paisano" desde las disimilitudes entre las cosmogonías:

En (la epístola a) los Romanos dicen que Dios los manda a la tierra prometida por un desierto, pero por allá fueron los egipcios, los hebreos, los alemanes, los rusos, los árabes, y allá no fueron los uitotos, ni los boras, muinane, ocainas; nosotros estábamos en medio de la selva, nosotros fuimos buscando don- 
de la rama de monillamena, y esa es la yuca que nosotros tenemos ahora, y allá fuimos nosotros, donde se sembró la yuca.

Según nuestra narración, lo que se dice ticunas, los yaguas, cocamas, ellos son de aquí mismo, especialmente son de aquí, que habitaban al borde del Amazonas, y allí donde nosotros fuimos, allá comenzando por curripaco, tucanos, carijona, yucuna, miraña, bora, andoque, muinane y murui, fuimos por allá... cogió la ramita de ese árbol y así fuimos quedando... Fuimos comiendo lombrices, esa yuca grande hasta encontrar el árbol, así nos contaron nuestros antepasados. Entonces nosotros estamos otra vez acá para soltar este amarre que nos está haciendo sufrir a nosotros (Muinane Marcelo, 2008, 19 de septiembre, relato oral. Mito de monillamena Abuelo Uitoto.rtf - 28: (6:9)).

O la afirmación de Miguel Ángel Sandoval, de padre yagua, madre ticuna y esposa uitoto, habitante de la comunidad Uitoto del km 11:

Yo me llamo Miguel Ángel Sandoval Dámaso. Hace 22 años que estoy viviendo en la comunidad del km 11. Llegué a conocer a Elsy Berenice, que es la mamá de mis hijos. Es a donde yo conformo acá mi familia y de esa manera yo me quedo. Así yo no sea de la etnia uitoto, yo soy de la etnia ticuna-yagua porque papá es yagua y mi mamá es ticuna, y yo, pues realmente estimo mucho a esta gente. Quiero a esta comunidad, me siento como si fuera yo de aquí mismo. Más yo quiero a esta tribu uitoto que querer a mis paisanos ticunas. Porque yo pues realmente le veo a esta gente de aquí muy querida, los abuelos, las señoras, los jóvenes que ahora llego a relacionarme con los muchachos, porque ellos me dijeron a mí: don Miguel, yo a usted no lo veo bailando (Sandoval Miguel Ángel, 2008, octubre, entrevista, km11_entrevista_sandoval.rtf - 10:1 (7:7)).
Es así como los "paisanos" se observan a sí mismos, plantean la unión, la comunicación a través de un mismo sentimiento y el compartir a través del tiempo y del contexto histórico. El siguiente relato hace parte del "mito de Monillamena" contado por el abuelo Marcelo Muinane Uitoto, de La Chorrera:

Puede ser Uitoto, Muinane, puede ser... pero allá es uno, allá no hay regiones diferentes para trabajar, a eso hay que poner mucho cuidado; yo vine aquí ustedes conocen mi nombre, Marcelo Muinane Uitoto, soy del corregimiento de La Chorrera.

Mira cómo son la bases donde nuestros antepasados estaban, era una chagra grande, allá se siembra yuca, chontaduro, caña, guamo y por encima de yuca para el bejuco de guamo unos a otros y así tenemos que hacer, cómo nos vamos a apoyar unos a otros, ustedes ticunas, ustedes yaguas. El que trabaja con bien, el que trabaja vive bien, si ustedes trabajan bien ellos también van a trabajar bien. (Muinane Marcelo, 2008, 19 de septiembre, relato oral, abuelo uitoto.rtf:-28:13 (16:17)).

Los que son de aquí, el cocama, ticuna y yagua, ustedes han visto sus abuelos, han visto sus papás, algunos ya no tienen papás, ellos cuando sus hijitos andaban con sus papás, y cuando murió sus papás ellos habían dejado un puente hecho para pasar de una quebrada a otra, después de muchos años ese ya no va a haber, ya se pudrió, entonces poner otra vez puente. Se dañó todo, pudrió, entonces toca poner otra vez puente para caminar por ese puente, se dañaron todo por allí esta escondido y se va encontrar, y se va encontrar otra vez la unión, uno cuando quiere hablar hablemos de frente (Muinane Marcelo, 2008, 19 de septiembre, relato oral mito de Monillamena, Abuelo Uitoto. rtf - 28:1 (5:8)). 
A partir de la categoría de paisano, también es posible afirmar que el blanco ocupa el lugar del "otro" para el indígena. El indígena no se reconoce en las narrativas de los blancos o mestizos. De esta forma, la comunicación es mucho más fluida entre "paisanos" y más compleja o casi imposible con los blancos, aún cuando estos últimos ocupen lugares similares de marginación, como el caso de la población migrante del barrio La Nueva Esperanza. Esta conclusión surgió durante los encuentros de proyecto que reunieron a las diferentes comunidades, a los cuales nunca asistieron los habitantes del barrio. Al respecto, algunos indígenas señalaron que "los blancos" no participan en proyectos de desarrollo que buscan la articulación con las comunidades indígenas. Esta situación genera dificultades para posibles proyectos futuros de integración cultural en entornos multiétnicos, como los barrios de los migrantes.

De otro lado, en los ámbitos urbanos (barrio La Nueva Esperanza) la condición trifronteriza incide en la visión que se tiene del "otro" peruano y del "otro" brasileño, aunque estos pertenezcan a cualquier etnia de la región. Prima la identidad nacional sobre la étnica, situación que ha generado que muchos de estos barrios se conviertan en territorios llenos de "otros", que buscan entre sí más argumentos de alteridad, diferenciación y fragmentación que de unión, articulación y comunicación. Más que un conocimiento intercultural, en estos entornos existen prejuicios que obstaculizan la consolidación de una esfera pública plural y diversa. La diversidad sigue siendo vista como un obstáculo para la integración y no como una fuerza que potencie el desarrollo sinergético.

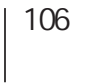

\section{Identidades múltiples: el Internado Indígena San Juan Bosco}

La existencia de los internados conlleva una separación de los jóvenes de su ambiente familiar y comunitario. Si bien los programas de etnoeducación han intentado adaptar los programas de educación nacional, en el caso del Internado San Juan Bosco, que alberga a muchachos provenientes de múltiples etnias amazónicas, es imposible hacer énfasis en el área etnoeducativa. Pues, tal como lo afirman algunos de sus profesores, ¿qué lengua se escoge?, ¿con cuál cultura se trabaja? El internado termina replicando la educación occidental, aunque reconozca la diversidad cultural. La mayoría de los alumnos de los niveles superiores terminan por olvidar sus comunidades, integrándose definitivamente al mundo occidental.

Durante el trabajo de campo en el Internado Indígena San Juan Bosco (Acercamiento y talleres San Juan Bosco, 2008, 10 de julio, diario de campo, rtf - 4:19. P4), la profesora Fidelina Gabba Ukubano de la etnia Uitoto explicó que trabajar el tema cultural con los muchachos es sumamente complicado. Pedagógicamente, realiza actividades lúdicas y recreativas a través de las cuales busca que los estudiantes de cada etnia muestren a los demás algo de su tradición desde su experiencia de vida. A esta dificultad se le suma el hecho de que muchos estudiantes no conocen su cultura. Muchos padres dejaron de enseñarles a sus hijos como respuesta a la marginación constante de su cultura frente a la sociedad nacional o dominante. La discriminación interétnica, la burla constante, la esclavización y la catequización dieron como resultado la negación de la 
propia cultura. Sin embargo, la profesora afirma que, de alguna manera, los muchachos han aprendido algo desde su cotidianidad.

Los estudiantes poco a poco van perdiendo el sentido de pertenencia a su etnia amazónica particular, pues el colegio queda muy cerca al casco urbano de Leticia, "en donde se enfrentan a la cultura del dinero". La profesora Fidelina (Acercamiento y talleres San Juan Bosco, 2008, 10 de julio, diario de campo, rtf - 4:19. P5) comentó que "al igual que la chagra se adapta a la naturaleza, los jóvenes se adaptan a su entorno". Esto no significa que los estudiantes pierdan su cultura, pues depende de la formación que se les haya dado y de la capacidad de asimilar los cambios. Hace énfasis en los muchachos que provienen de comunidades alejadas, educados en las malocas y en las chagras. En la ciudad sus necesidades cambian y también las formas de suplirlas. Ahora responden a la cultura occidental, de cierta forma globalizada. Algunos utilizarán los conocimientos adquiridos para aplicarlos en sus comunidades de origen. Otros no regresarán, se quedarán en la ciudad (Acercamiento y talleres San Juan Bosco, 2008, 10 de julio, diario de campo, rtf - 4:19. P4). Este proceso de transformación que se genera en los jóvenes se hace evidente en la siguiente entrevista: (Matapí Yucuna Walberto, 2008, octubre, entrevista rtf -,15:3 P15 Walberto [W] Johanna [J]).

J: ¿Tú llegaste solo?

W: Sí, solito, sin guía, sin nada; entonces con el tiempo fui adaptándome a entender el lenguaje que utilizan acá, fue muy diferente, mis compañeros de acá del río porque ellos pronuncian digamos su hermano, sí, y cuando yo digo su hermano tú te refieres a tu hermano, pero ellos no, ellos dicen su hermano de él, o su papá de él, y entonces fue un choque para mí. Las comunidades del río hablan pero yo no entiendo, el ticuna es diferentísimo al yucuna.

J: Háblanos un poco de tu comunidad.

W: Mi comunidad por nombre lleva Puerto Nuevo, y queda sobre el río Mirití, los grupos que predominan en esa comunidad Matapí, Yucuna y algunos también blancos. Allá se manejan dos cosas fundamentales, digamos el mundo tradicional, o sea el conocimiento del chamán, entonces ese es el que sobresale, y como en segundo nivel está el occidental.

J: ¿Pero está la cultura occidental?

W: Sí está, sí está, entonces en el campo de educación, de salud, el maestro tiene que ser conocedor del mundo occidental y de su propia cultura, y entonces se enseña de cero a tercero en idioma, abecedario, todas esas cosas en idioma, de ahí en español hasta terminar. $Y$ en la salud es lo mismo, el promotor de salud es como el segundo del chaman, del médico tradicional, él es el que recita, dice si se puede remitir al hospital, digamos, él dice si se puede, le dan plantas y pastillas como complemento.

$\mathrm{J}$ : Y por ejemplo tú que ya acabaste el colegio, ¿cuáles son tus expectativas ahora, qué quieres hacer?

W: Aprender dos cosas: mi cultura y yo quiero estudiar, mi cultura no me dedico mucho porque es lo mismo casi en su totalidad, todo lo que tiene que ver en el dominio del canto, historias, maloca, por ejemplo cosas como curar como los chamanes todavía no lo manejo. 
J: ¿Y cuánto se demora el viaje para llegar a tu comunidad?

W: De aquí una hora en avión, de allí 14 ó 16 horas en bote.

\section{$[\ldots]$.}

W: Yo creo que aquí he estado pendiente de la cosas del comportamiento de los pelaos y uno se da cuenta de muchas cosas y conoce. Además de conocer, aprende que somos de diferentes, digamos, rangos, y diferentes capacidades de tener o no algo como los diferentes utensilios aquí en el internado. $\mathrm{Y}$ entonces, los que no tienen la suficiente capacidad se sienten. ¡Yo lo he visto! Hay pelaos que pasan su completo periodo académico, digamos todo el año lectivo, sin visita, sin ni una visita, a veces con dos o tres encomiendas que reciben, tres barritas de jabón, cepillo, un tubito de colgate y eso no aguanta, y uno ve, yo distingo muchos padres de acá que uno va y encuentra por allá todos borrachos y uno se da cuenta de que se preocupan más ellos por autodestruirse que apoyar pues la educación de los hijos, y entonces alguno por esas necesidades surge la apropiación de las cosas de los demás. Pues claro, necesita, no tiene jabón y dónde puede conseguir y acá solo; a mí me ha tocado mandarles a varios pelaos porque es que uno se da cuenta, yo soy uno de los que ayudo también hasta donde me alcance. Uno se da cuenta porque llegó un momento que a mí me sucedió eso, que yo no tenía absolutamente nada por el Mitú que andaba, llegaron unos muchachos y me dejaron sin nada, sin bolsa y en una ciudad, dónde llegar, pues yo recién llegado y entonces tuve una suerte que vino una señora ya mayor de edad, me recogió y me dijo: “iMuchacho! Ayúdeme a recoger algo", y me quedé en esa casa, y así renací otra vez.

\section{$[\ldots]$.}

Acá hay muchas cosas que suelen pasar, el alcoholismo en los demás, aquí uno se da cuenta de los corregimientos de los ríos, de qué corregimientos son los que más salen a tomar, que yo lo he hecho, entonces listo, la gente del Mirití no, pero mientras de acá a veces llaman tres veces a las demás y uno esa gente no, uno a situando.

\section{$[\ldots]$.}

Bueno, pues sí, generalmente mi familia es un núcleo ejemplar para mí, porque mi papá se ha caracterizado mucho en el liderazgo en las políticas indígenas, en la lucha indígena.

J: ¿En el colegio qué otras personas vienen de allá?

W: Bateliano de décimo otro que se fue también del grupo étnico letuama, que hablan también igual como pasa Matapí -Yucuna funciona ese idioma para dos grupos étnicos, tal vez porque son completos, como decir en el español algo que escriben con tilde y se pronuncia sin tilde entonces listo como si alfil con tilde o sin tilde, listo, vamos por eso, vamos combinando y se llega a concluir de que, listo, usted habla esto y nosotros también y nos entendemos.

\section{J: ¿Cuántos hermanos tienes? \\ $\mathrm{W}$ : Tengo siete.}

J: ¿Los otros piensan estudiar acá?

W: Tengo dos estudiando en Pedrera, ya no vienen acá porque ya hay colegio, entonces les facilita más porque allá uno tiene constante visita de familia, baja, se va, le mandan algo porque hay embarcación, pero acá quién. (Risas) 
J: ¿Qué música te gusta?, ¿cambió tu gusto al estar acá?

W: El reguetón; no, yo combino, yo hago mis cosas siempre he dicho yo hablo, sé unos ciertos bailes y cantos, yo he bailado, de alguna forma me hago sentir como parte del grupo de los que organizan bailes rituales allá, yo siempre digo eso es allá, eso es mi punto fundamental, jugar eso es allá y si estoy acá démosle acá. Igual si se llega a hablar. Pero igual si se llega hablar, como en este caso ya hablando ya te toca hablar de allá.

\section{FORMAS Y ESTRATEGIAS DEL DESARROLLO ENTRE COMUNIDADES MULTIÉTNICAS Y PLURICULTURALES}

Con respecto a la categoría de desarrollo, sobresalió la primacía de enfoques tecnológicos y económicos. Estos se hacen presentes no solo en las instituciones que lideran los proyectos, sino también en las concepciones de los líderes indígenas. Muchos de los programas no trascienden la perspectiva del subsidio, la ayuda y los recursos externos. Por el contrario, prima el asistencialismo, dinámica que genera dependencia de las comunidades hacia las instituciones gubernamentales.

Muchos de los proyectos privilegian un modelo de desarrollo occidental, sin tener en cuenta ni las condiciones geográficas, ni climáticas, ni los sistemas económicos tradicionales. Esto desembocó en la generación de prácticas contrarias a la identidad indígena, como el monocultivo, el cultivo de productos para la venta externa sin satisfacer el abastecimiento interno y la compra de productos que antes eran generados en la chagra, lo que trae entre otras consecuen- cias el desequilibrio nutricional, el cambio de roles tradicionales y la dependencia del mercado.

En la relación entre comunicación y desarrollo, han primado procesos centrados en la información y el difusionismo tecnológico. Los procesos mediáticos entre los indígenas, además de ser escasos, se centran en el manejo técnico de aparatos de registro, como cámaras de video y de fotografía, sin plantear un uso crítico y acorde con las necesidades de las comunidades. Además, carecen de continuidad debido a que quienes participan en las capacitaciones respectivas no cuentan con posibilidades de utilizar las habilidades y multiplicar el nuevo conocimiento entre sus comunidades. Por lo general, este tipo de programas se plantean desde el interior del país pensando en públicos masivos.

Además, institucionalmente se siguen utilizando prácticas de la comunicación unidireccional, como el marketing social y la imitación de líderes públicos, que buscan generar cambios en los comportamientos observables desde estímulos externos, sin que ello signifique una comprensión real de la situación que se pretende transformar.

Asimismo, después de realizar un acercamiento a los medios de comunicación masiva existentes en la zona, podemos afirmar que hay una participación mínima de la población indígena en ellos (radio y prensa). Solo en una de las emisoras se dedica una hora semanal a las organizaciones indígenas sin involucrar a la población de base. Pese al interés de las comunidades frente a la radio, la orientación de las emisoras es fundamentalmente comercial y no de servicio, visibilización y articulación entre esos 
grupos. La radio sigue siendo un medio principalmente de información y no de comunicación.

A pesar de esta visión unidireccional del desarrollo y la comunicación, debemos resaltar por su parte el papel que han cumplido los planes de vida ${ }^{3}$ dentro de las comunidades indígenas. Estos planes se han convertido en una estrategia fundamental para expresar necesidades y gestionar recursos ante el Estado con base en su cultura. De hecho, posibilitaron la generación de espacios de encuentro e intercambio entre etnias, lo que las ha fortalecido y cohesionado, y produjo maneras diferentes de negociar en igualdad con las instancias gubernamentales. Desde su visión indígena y a la vez institucional, Emperatriz Cauhache, directora de CODE$\mathrm{BA}^{4}$, define los planes de vida como:

Un instrumento político, para nosotros es un instrumento muy importante porque es la que ordena al interior de las comunidades, al interior de la asociación al reflejar lo que somos, lo que queremos, lo que hacemos y lo que anhelamos ser el día de mañana en coordinación con las instituciones. Y aún más, los planes de vida vienen

3 El sistema de monitoreo de la protección de los derechos y la promoción del buen vivir de los pueblos indígenas de América Latina y el Caribe define los planes de vida como "La ruta, la materialización del desarrollo propio: acciones y programas especificos. Para su implementación, deberán de contar con la dotación presupuestal necesaria por parte del Estado. Está basado en la oralidad de su cultura y en la revitalización de las tradiciones. Constituye una herramienta útil para promover los procesos de reflexión de los mismos indigenas acerca de sus dinámicas sociales, culturales y económicas, y alcanzar algún nivel aceptable de formalización de los mismos, sin reducirse al formato relativamente rígido de planes de desarrollo".

4 "La Corporación para la Defensa de la Biodiversidad Amazónica - Codeba- es una organización sin ánimo de lucro, fue creada el 7 de mayo del 2001 a iniciativa de los abuelos del pueblo cocama para ayudar en la preservación y consenvación del ambiente y biodiversidad amazónica" P24 institucion_codeba_emperatriz. If - 2434 Namos a hablar acerca de la Co.] (3:3). a ordenar los recursos nuestros, a no malgastar estos recursos, porque anteriormente llegaba el alcalde cien, doscientos, un millón para una cosita, la otra, y eso se quedaba en los bolsillos de otros y no llegaba la plata a donde tenía que llegar (Cauhache Emperatriz, 2008, noviembre, entrevista, rtf- (24:31 (15:16) P24]).

En la región del trapecio amazónico estos planes hacen parte del mencioando "programa amazónico" que, como lo expresa Emperatriz Cauhache, se originó a partir de la unión entre diversas instituciones regionales:

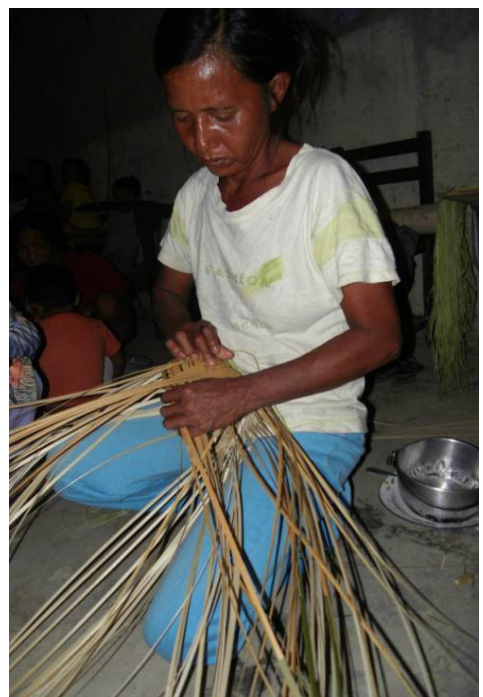

Figura 9. Desarrollo alternativo: las base de un canasto. Taller San Sebastián de los Lagos 2008. Septiembre.

Era la primera vez que nos lanzábamos en esta iniciativa todos juntos, unidos, las asociaciones, las autoridades, los jóvenes, los abuelos, los líderes; era hacer una reflexión, como acompañar y fortalecer los procesos de reflexión que se venían dando en todos los niveles, organizativo, político social, cultural. Todos. Y, sobre todo, fortaleciendo el gobierno propio de los pueblos indígenas, así es como nace prácticamente el programa amazónico, con esas líneas, 
el programa amazónico no es un programa como de pronto nosotros conocemos, si no que es un programa que se construye con las comunidades, que viene a sumarse a la expectativa de los pueblos indígenas por eso es que ha tenido mucha apropiación por parte de los pueblos indígenas, porque lo han sentido suyo (Cauhache Emperatriz, 2008, noviembre, entrevista, rtf- (24:31 (5:5) P24]).

El centro de programa amazónico son los planes de vida, vienen a apoyar, no porque nosotros no tengamos nuestros planes concretos, sino que... nosotros tenemos nuestro plan de vida, está oralmente en cada pueblo, son nuestras propias políticas es el quehacer es la vida cotidiana que llevamos. Qué es lo que la corporación Codeba ha hecho... lo que viene es a facilitar a través del programa amazónico, de los recursos del programa amazónico, ayuda que eso se escriba, entonces nos dan sus comités de relación, líderes indígenas que ya escriben en español, empezamos a orientar en la escritura , las actas, las memorias de cada encuentro (Cauhache Emperatriz, 2008, noviembre, entrevista, rtf- (24:10 (5:5) P24).

A partir de allí, las organizaciones indígenas han sido protagonistas en la escritura de los planes de vida y, al mismo tiempo, a la formulación de programas y proyectos ajustados a los mismos.

Nosotros hacemos desde la corporación es escribir los planes de vida y descubrir entre todos la metodología, vamos a escribir, no se va a formular porque ya está formulado, ya está construido el plan de vida, vamos a escribir nuestra vida, nuestras políticas a blanco y negro, en papel, escrito, para que tenga validez, no para nosotros, para nosotros ya tiene el reconocimiento y la validez, pero para el lenguaje no indígena se necesita tener en lenguaje escrito para que tenga alguna validez y entre a articular con el plan de desarro- llo municipal y departamental, por eso el trabajo de la corporación se hace facilitando, no la formulación, sino escribiendo los planes de vida que lo hace el equipo, se nombran tres o cuatro personas de los grupos indígenas con los representantes de la alcaldía.

(Cauhache Emperatriz, 2008, noviembre, entrevista, rtf- (24:13 (7:7) P24).

Como es evidente en esta cita, esta metodología de escritura ha contado con la participación de líderes de las comunidades, pero no con las comunidades en pleno, por razones operativas. Es quizás por ello que las comunidades saben muy poco o nada sobre estos procesos.

Según Emperatriz Cauhache, a partir de los planes de vida, los proyectos se han dedicado al "rescate de la identidad cultural de los pueblos del trapecio del departamento del Amazonas, buscando la sostenibilidad financiera de cada uno de ellos, o sea, cómo hacer que los indígenas sean cada día más independientes, más autónomos, en sus tomas de decisiones" (Cauhache Emperatriz, 2008, noviembre, entrevista, rtf- (24:2 (3:3) P24).

Entonces, los planes de vida, si bien hacen parte de las maneras como la forma de ordenamiento territorial occidental busca ubicar en la norma a los indígenas, han posibilitado ejercicios de reflexión, unión y gestión que se visibilizan en el fortalecimiento de las instituciones y en la unión entre diferentes comunidades étnicas. Las dinámicas propias de las instituciones han imposibilitado una participación más directa de los integrantes de las etnias en sus procesos; por ello, es crucial buscar espacios de encuentro y participación más amplia que garanticen la apropiación de dichos documentos. Este requisito se hace aún más pe- 
rentorio si se tiene en cuenta que desde ellos se regula la acción de los gobernadores indígenas y los alcaldes municipales en torno a las comunidades indígenas.

\section{Planes de desarrollo desde el Estado}

El Estado colombiano lidera actualmente diversos programas que se imparten de manera homogénea para todas las comunidades indígenas y rurales del país. Ese es el caso de Familias guardabosques, orientado a incentivar cultivos "tradicionales" con posibilidades de apertura hacia el mercado que sustituyan la siembra de coca.

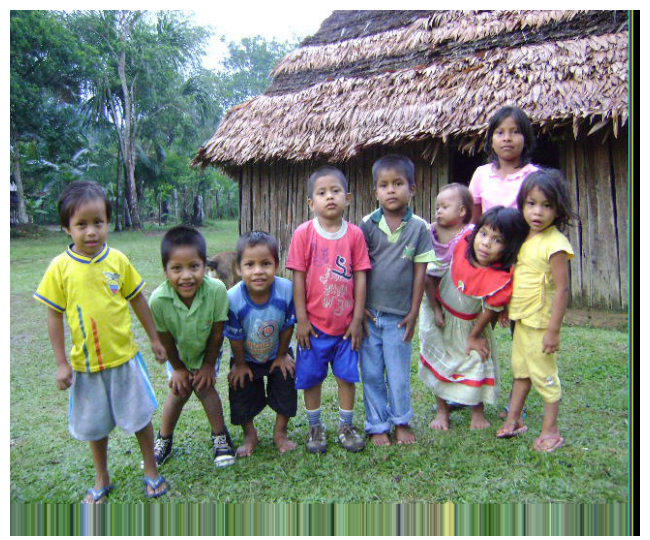

Figura 10. Pancarta anunciando el programa estatal de Familias Guardabosques.

El programa Familias guardabosques se enfoca hacia un solo proyecto con diferentes ramas: el énfasis es chagra, pero de allí sale piscicultura, avicultura, miscelánea, modistería, sale la misma chagra integral, la siembra de arroz, carnes y lácteos. Son ocho proyectos identificados que nos dan las mismas comunidades para que podamos desarrollarlos en el término del programa, porque estamos en esa fase, en ejecutar (Alvear Peña, Nilson, 2008, noviembre. Entre- vista realizada por Rodríguez, J. y Cortés, D. Leticia).

Este programa de desarrollo conduce a una resignificación de las chagras, de la dieta alimentaria, de los tipos de cultivos, así como en las actividades propuestas para los integrantes de las comunidades. Sería interesante contrastar hasta qué punto roles como el de la modistería o la producción de carnes y lácteos surgen del interés de los integrantes de la comunidad. Asimismo, hechos como la piscicultura, la avicultura y la ganadería contradicen la relación de los indígenas con un territorio de selva tropical húmeda, que se autorregula y que requiere más ser entendido o hacer parte de él que controlar.

Por su parte, el investigador Juan José Vieco (2009) plantea que estos programas obedecen a intereses económicos y políticos de orden global y nacional, más que a una relación directa con el desarrollo local:

El programa de Familias guardabosques, actualmente en ejecución, tiene como punto de partida la entrega por parte del Estado, en este caso de un programa político estratégico del presidente Uribe y su gobierno, de un subsidio de 420.000 pesos. De estos dineros, para el caso de las comunidades del resguardo Ticoya de Puerto Nariño, de 210.000 pesos en efectivo para cada una de las personas certificadas por el resguardo y 210.000 pesos de ahorro obligatorio por medio de una cuenta de ahorros del Banco Agrario. El programa, en términos generales, tiene por objeto reforzar los sistemas productivos y la seguridad alimentaria para que las familias no se vean obligadas a destruir la selva con el fin de sembrar la hoja de coca. De esta forma, el programa cumple con requisitos internacionales (la protección de la selva 
amazónica), nacionales (se eleva la calidad de vida de los pueblos marginados y se aseguran algunos "voticos") y locales (se incentiva el mercado local debido a la inyección de dinero en efectivo y se fortalecen los lazos y dependencia política de las comunidades de los actores sociales y económicos que detentan el poder local).

Además del dinero en efectivo, las comunidades recibieron herramientas (machetes, limas, azadón, pala, palín), semillas y técnicas de siembra (elaboración y utilización de compost, sistemas de cajoneras). Como en el caso anterior y de manera previsible, las herramientas, de muy mala calidad, sirvieron el tiempo justo de permanencia de los funcionarios gubernamentales en la comunidad; de las semillas, solo algunas hortalizas y gracias al especial cuidado de las señoras sobrevivieron; los sistemas de compost y de cajoneras, traídas por los funcionarios como la gran novedad, no solo eran ya conocidas por todos, sino que las señoras tenían más familiaridad y destreza que los técnicos encargados de los talleres de capacitación (p. 70).

Otro de los aspectos que se resaltan en este proyecto es la integración de los indígenas al mercado a través de la venta de productos a los ciudadanos del casco urbano de Leticia, para muchos de los cuales los indígenas son sujetos "perezosos" que no cultivan lo que la ciudad requiere y que viven de los subsidios del gobierno: “(...) hemos realizado a través de las familias ya un primer mercado, ya vamos para un segundo mercado: canasto de la abundancia indígena, en donde estamos demostrando a la ciudadanía en general que sí estamos cosechando alimentos para la canasta familiar no solo para nuestras familias sino también para la ciudadanía en general y los leticianos" (Alvear Peña Nilson. 2008, noviembre, entrevista. Rtf- 23:25 (11:11) P23). Es evidente la intención de legitimar el pro- grama desde su funcionalidad para las familias externas a las comunidades.

También el programa Familias en acción implica la realización de convenios con Acción Social y la existencia de subsidios otorgados a las familias después de tres meses de inscripción. Entre los logros de este proyecto se encuentra la construcción de cinco malocas cofinanciadas por Corpoamazonia (Alvear Peña Nilson. 2008, noviembre, entrevista. Rtf - 23:29 (12:12) P23), así como la generación de empresas comunitarias de agua potable, en conjunto con el Ministerio de Agricultura. Estos proyectos, al igual que otros aún no ejecutados, posibilitan el fortalecimiento de relaciones interinstitucionales que permiten "buenas conexiones, buenos empalmes, buena coordinación, de tal manera nos hemos fortalecido como organización" (Alvear Peña Nilson. 2008, noviembre, entrevista. Rtf- 23:33 (14:14) P23).

De todo este trabajo interinstitucional, el líder de la organización resalta logros materiales y tecnológicos como "una infraestructura, con vehículo, transporte intrafluvial, servicio de cómputo para las familias y las comunidades que están afiliadas" (Alvear Peña Nilson. 2008, noviembre, entrevista. Rtf- 23:34(14:14) P23). Todo esto posibilitó a Azcaita, según Nilson Pinto, obtener el mayor puntaje en la licitación para ser elegida como la organización que acompañe el programa Familias guardabosques productivas.

\section{Consecuencias del desarrollo tecnológico y económico en la vida de las comunidades}

Entre las principales consecuencias de estos programas, los indígenas participantes 
en las actividades señalan que "les dan un dinero para que ellos siembren productos en la chagra y de esta manera los puedan vender en el mercado. Esto ha conllevado a que la chagra sea meramente de monocultivos de yuca o plátano para obtener dinero y con ese dinero se compra, curiosamente, los alimentos que se han dejado de producir en la chagra" (P 5: Trabajo con instituciones. rtf - 5:3 [Aproximadamente en el séptimo..] $(15: 15)$. Tal como lo habíamos señalado en el capítulo referente a los aspectos identitarios, las chagras perdieron además su dimensión simbólica como elemento constitutivo de la cultura. A esto se suma que los indígenas cambiaron su rol de productores para pasar al de consumidores, lo cual no solo afecta la cultura, sino también la salud:

La base de la salud es la chagra, porque es la que nos da de comer y tiene de todo para la economía. Pero los pueblos hemos ido cambiando la alimentación propia por otra. Los productos ancestrales se están cambiando, vendemos el alimento sano que producimos para comprar alimentos contaminados. Por tanto, debemos desarrollar las iniciativas productivas que planteamos en los planes de vida (Mandato indígena, 2008, septiembre 20 .rtf - 29:28 (27:27) P29).

En términos económicos, uno de los mayores problemas que hacen visibles las comunidades participantes de estos programas tiene que ver con la escasez de tierras para el cultivo, el hecho de haberse convertido en consumidores y la falta de recursos para extractar los insumos imprescindibles para el desarrollo de su cultura material -artesanías, alimentación- , como la chambira y la yanchama, fibras vegetales con las que se tejen mochilas y se elaboran vestidos: “(...) ellas saben hacer sus artesanías, unas hamacas, sus paneros, pero no tienen materiales, por la tala de árboles" (Taller pescando el conocimiento de la cultura ticuna. Diario de campo. rtf - 31:6 (22:22) P31). Asimismo sucede con las chagras, que solían ser amplias y hoy en día, debido al crecimiento poblacional, experimentan reducciones significativas.

Estos proyectos tienen además el agravante de adolecer de visiones sostenibles, ya que han contado con estrategias pobres para tener continuidad "incluso cuando los animadores y asesores externos hayan concluido su contrato y hayan abandonado la comunidad. No contaron con el conocimiento local ni con la larga experiencia acumulada de las comunidades con proyectos de desarrollo y con las instituciones públicas y privadas" (Vieco, 2009, p. 13).

Al respecto, las soluciones propuestas por los mismos habitantes indígenas tienen que ver con la capacidad para articular el conocimiento indígena con las oportunidades que ofrece la cultura occidental. Así lo señaló Miguel Ángel Sandoval:

... los indígenas tenemos la ventaja de que conocemos lo indígena y nos podemos mover en lo que los blancos saben, conocen y vienen a proponernos. Uno no puede perder lo indígena pero tiene que aprovechar y mezclar con lo bueno de los blancos" (Sandoval Miguel Ángel, 2009, mayo 25, entrevista).

Asimismo, en la cumbre del mandato indígena, otro de ellos alude a los retos de la economía actual: "Sabemos que hoy la economía es diferente a la que vivieron nuestros abuelos, que necesitamos dinero para muchas cosas, que debemos proyectar nuevas iniciativas económicas, pero sin olvidar lo nuestro" (Mandato indígena, 2008, septiembre 20, rtf- 29:29(29:29) P29). 
De otro lado, el monocultivo, referido también en estos testimonios, resulta un método contrario no solo a las tradiciones indígenas, sino también al suelo amazónico, el cual, por su pobreza en minerales y materia orgánica, no puede explotarse extensivamente, sino que requiere del cultivo de múltiples especies, con descansos y quemas periódicas, tal como se hace en las chagras tradicionales. "Por eso nos preocupa la situación de tierras de las comunidades del trapecio (amazónico)" (Mandato indígena, 2008, septiembre 20, rtf- 29:9(14:14) P29).

Este recorrido por las formas como el desarrollo tecnológico y económico se asume en las comunidades desde ellas mismas y desde proyectos externos a ellas nos ha permitido identificar diversos aspectos. Entre ellos se encuentran: la preponderancia de lo económico cuando se piensa en el desarrollo en estos grupos indígenas suburbanos, lo cual, en algunos casos, obstaculiza la incorporación de dimensiones simbólicas, históricas y del territorio a estas iniciativas; la visión funcional de las instituciones $\mathrm{u}$ organizaciones líderes del desarrollo hacia las comunidades y los individuos que las conforman, con funciones definidas de antemano en los proyectos generados desde el centro del país; la adaptación de los grupos indígenas a los proyectos de desarrollo del país, como Familias en acción y Familias guardabosques, lo cual implica transformaciones en sus dietas alimentarias y en sus costumbres en el uso de recursos, que, cada vez más, se adquieren en el mercado y cada vez menos producidos por ellos mismos, con lo cual los indígenas ingresan en la lógica del empleo; esa misma acomodación a través de los planes de vida, los cuales han supuesto un traslado de la tradición oral a la escritura en busca de una validez externa del pensamiento indígena; $y$, finalmente, el papel de la educación y de la comunicación como procesos que ofrecen un bienestar y una recompensa inmediata en lo económico, en nombre de los cuales existe un amplio sacrificio de otras dimensiones sociales y culturales.

\section{La radio: espacio alternativo de los jóvenes}

El hecho de poseer algunos equipos y de realizar "una serie de actividades para recolectar fondos y complementar los equipos que tenían" motivó a los estudiantes y profesores de la Institución Educativa San Juan Bosco a comentarnos acerca de la iniciativa de generar una emisora. Esta iniciativa, mencionada en mínimas ocasiones entre otras comunidades, se centra en la idea de "abrir un espacio en el que los estudiantes puedan expresar sus pensamientos y comentaran las problemáticas que tienen en el colegio. Además, tener un espacio para que ellos puedan escuchar música y aprovechar el tiempo libre en el uso de la emisora, un medio para reforzar los movimientos estudiantiles y como un canal de información abierto, en el cual toda la comunidad pueda participar" (Talleres San Juan Bosco, 2008, agosto. .rtf - 4:24 (112:112)P 4).

En uno de los talleres realizados para este fin, "recalcamos que antes de aprender el manejo técnico de los equipos, debemos aprender a crear contenidos apropiados para el lenguaje radial, que tengan una intención y un objetivo claro, ya que de esta manera se puede entender que la radio no es solo el aparto físico sino que contiene una serie de características implícitas que hacen que la radio sea uno de los medios de comu- 
nicación con mayor acogida en el mundo" (Taller: jóvenes explorando la radio, 2008, 2 de agosto. $\mathrm{rtf}-4: 24$ (112:112) P 4).

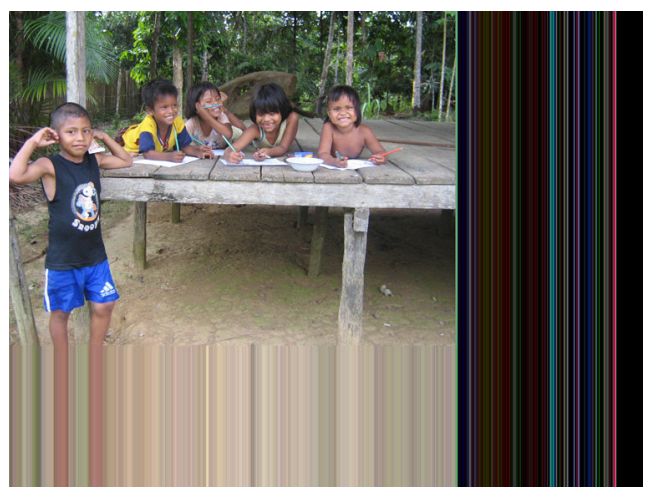

Figura 11. Jóvenes explorando la radio. Taller en el San Juan Bosco, instalaciones del Sena 2008, septiembre. Fotografía tomada por: Rodríguez Caballero, J.

A lo largo del proyecto, los talleres realizados permitieron, con el apoyo técnico del SENA, abrir espacios para la reflexión, el cuestionamiento y la expresión del significado de ser indígena hoy en un contexto multiétnico, como el Instituto San Juan Bosco, $\mathrm{y}$ en un territorio proclive a la hibridación cultural como Leticia. Al respecto, algunos de los programas posibilitaron la expresión de los relatos míticos en las lenguas indígenas, abrieron espacios para la confrontación de los jóvenes que aún no reconocen el valor de su cultura y posibilitaron manifestaciones culturales juveniles que tuvieran en cuenta el carácter étnico de esta población.

Entre los recursos utilizados por los jóvenes se encuentra el del radioteatro. Este permitió a algunos de los grupos explicar la problemática del robo, un tema crucial para la convivencia en la institución, si se tiene en cuenta que se trata de un internado en donde adquirir los utensilios de aseo requiere amplios esfuerzos económicos y de desplazamiento por parte de las familias.
El otro grupo fue liderado por Walberto Matapi, un joven de grado 11, ellos querían denunciar la problemática que había en el colegio del robo, ellos nos pidieron explicación de cómo hacer el dramatizado. Dimos la explicación a los dos grupos, diciendo que tenían que elegir unos personajes, un parlamento para los personajes, pensar en posibles sonidos a utilizar y en crear una historia como primer lugar. Les dijimos que era como hacer una obra de teatro con la diferencia que los compañeros no los iban a ver sino a escuchar, por lo tanto tenían que ser muy creativos en la forma de presentar el dramatizado (Taller jóvenes explorando la radio, 3008, 4 de agosto. Rtf- 4:30 (157:157).P 4).

De otro lado, la misma radio se identificó como un medio para la consecución de recursos, tal como lo demostró un grupo de estudiantes que, en estos talleres, organizó un programa de radio comercial. "Quisieron promocionar una 'coca cola bailable' para recoger fondos para los implementos que hacían falta de la emisora" (Taller jóvenes explorando la radio, 2008, 4 de agosto. Rtf- 4:30 (157:157).P 4).

Algunos de los talleres permitieron evaluar la radio como "un medio con el cual podemos aprender de una manera divertida, ya que son jóvenes y les gusta aprender de una manera lúdica" (Taller jóvenes explorando la radio, 2008, 4 de agosto. Rtf- 4:26 (122:122).P 4). Asimismo, en algunas carteleras en el taller, otros jóvenes se refirieron a "la comunicación como medio de participación juvenil":

La otra cartelera tenía colores llamativos y mucha decoración, el contenido de esta hacía alusión a la importancia de que los jóvenes se vincularan al proyecto, ya que el éxito del proyecto radicaba en la amplia participación de los estudiantes. Los jóvenes de este grupo 
explicaron que se dividieron el trabajo estético y que entre todos pensaron en el contenido que iban a poner. Les pedimos que colocaran las carteleras en los lugares del colegio donde ellos sabían que la gente a diario pasaba para que las pudieran leer" (Taller jóvenes explorando la radio, 2008, 4 de agosto. Rtf- 4:27 (123:124) P 4).

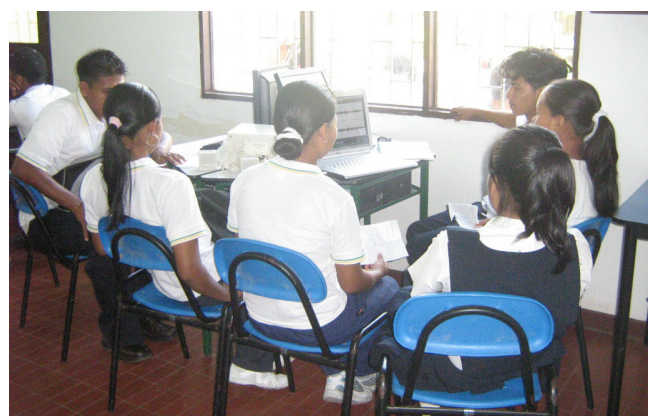

Figura 12. Jóvenes Explorando la radio. Taller en el San Juan Bosco, instalaciones del Sena 2008, septiembre. Fotografía tomada por: Rodríguez Caballero, J.

De este modo, la radio, desde los jóvenes, se constituyó -incluso cuando tenía un carácter comercial- en un espacio de expresión de sus ideas, en una forma de comunicación que permitió -al menos por el periodo de duración del proyecto- reflexionar sobre su realidad, hacerla evidente a ellos mismos y a los demás, y visibilizarse ante otros públicos que los desconocen. Resulta crucial pensar, desde lo mediático, el papel de la radio en la integración de las culturas, en la visibilización de sus problemáticas, en la gestión de las mismas y en la resignificación de la importancia de las diferentes manifestaciones culturales étnicas que habitan esta zona. (t 3) Formas del liderazgo pluricultural Frente al tema del liderazgo y la ciudadanía, es posible afirmar que las comunidades multiétnicas con las que trabajamos tienen en sí mismas ya una noción de lo público, los derechos, la libertad y la ciudadanía. No es necesario imponer visiones externas, por el contrario, es importante reconocer los discursos, prácticas y fundamentos culturales -como la tradición y la cosmovisión- sobre los que reposan estos conceptos. Dichas nociones se sustentan en conocimientos míticos y religiosos. La mitología ordena la convivencia en las comunidades y es la base de la visión indígena frente a los derechos.

A partir del reconocimiento que la Constititución de 1991 hizo a la plurietnicidad y a la multiplicidad como condición característica del país, se reafirmó la jurisdicción especial indígena. Ese tratamiento diferencial ha sido aprovechado por algunas comunidades que tiempos atrás negaron su condición indígena con el fin de escalar socialmente, y hoy en día vuelven a reclamar por sus orígenes para alcanzar dichos derechos. En ese sentido, puede identificarse una visión funcional de la identidad indígena, es decir, su utilización para ascender posiciones y satisfacer necesidades, lo cual ha incidido, en ciertos casos, en el uso de las raíces indígenas con fines individualistas por encima de los intereses de la comunidad.

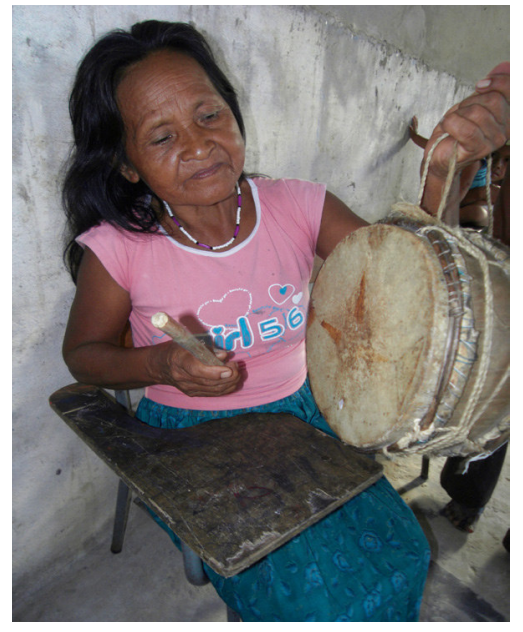

Figura 13. Instrumentos: medio de manifestación cultural. Abuela de la comunidad San Sebastián de Los Lagos, 2008, diciembre. Fotografía tomada por: Rodríguez Caballero, J. 
En los estilos de liderazgo debe destacarse el papel que han desempeñado las mujeres. Ellas ocupan un lugar trascendental en las sociedades indígenas por su función en el consejo de ancianas, en la chagra, en el proceso de crianza y educación de las nuevas generaciones, en la transmisión de saberes ancestrales, en la participación en las asambleas y en la gestión de proyectos con algunas instituciones estatales. Día a día han ganado fuerza y visibilidad frente a lo público. En el caso de las indígenas ticunas, esta fuerza tiene sus raíces en el lugar que ocupa la mujer en la cosmovisión de la etnia, lo cual se expresa en el ritual de la pelazón.
Por su parte, la situación del liderazgo y la participación en el kilómetro 11 hace pensar en la importancia de estrategias que permitan superar la centralidad de los intereses personales y la fragmentación de la comunidad. Resulta importante buscar espacios de cooperación en los cuales se rescate el sentido de lo comunitario, se busquen formas de trabajo conjunto entre las familias y se superen los intereses económicos que derivan también de la falta de reconocimiento al otro.

\section{Nuevos retos para una comunicación multicultural}
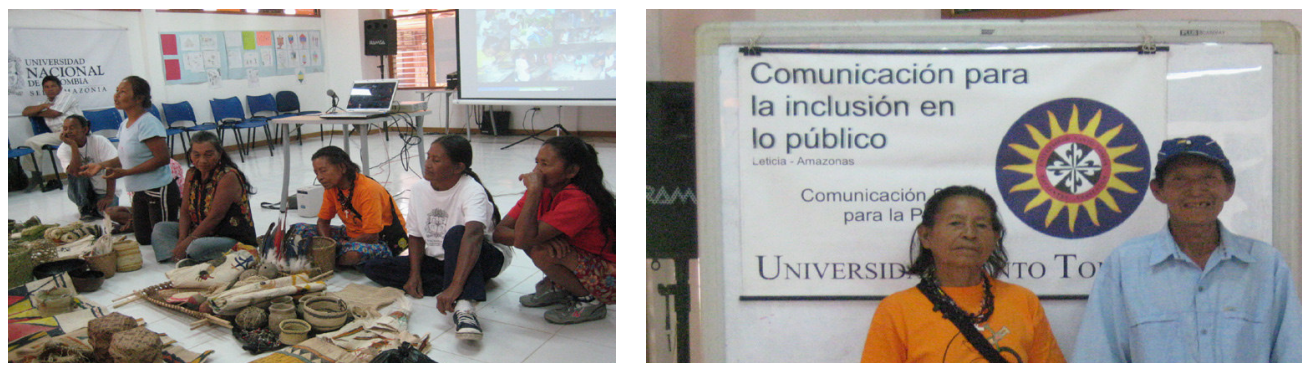

Figura 14. Encuentro articulador. Universidad Nacional. 2008, diciembre. Fotografía tomada por: Herrera Arango, A. y Uruburu Gilède, S.

Uno de los mayores aportes de esta investigación fue la creación de un espacio de diálogo intergeneracional para el fortalecimiento de la cultura tradicional. Estos espacios, consolidados a través de talleres y diálogos de saberes, ofrecieron la posibilidad de ser escuchado, de expresarse y de reunirse en torno a elementos festivos, como la música tradicional, los instrumentos musicales, el baile y los juegos. Lo mismo sucedió en torno a elementos de la cultura material con utilidad cotidiana -como el panero, la escoba, las tinajas, entre otros-. Estos permitieron trascender la "exotización" y "fol- clorización" de la cultura por parte de los jóvenes y generarles interés al mostrarles sus posibilidades de uso actual. En consecuencia, los jóvenes demostraron su deseo de continuar los procesos de aprendizaje iniciados en el trabajo de campo: se abrió un espacio de comunicación intergeneracional.

Se renuevan las relaciones comunitarias, se toman las decisiones, se planifica el futuro, se transmite el conocimiento, se establecen relaciones de vecindad y de cooperación con diferentes núcleos familiares y comunitarios, y se generan los elementos identita- 
rios que hacen visible a la comunidad frente a las otras. En estos espacios de comunicación tradicional se hace evidente la articulación entre la cultura y la política.

Con base en lo anterior, recomendamos fortalecer los espacios culturales, como la cumbre de ancianos, las fiestas de la pelazón, las reuniones en la maloca, los consejos de ancianos, los bailes tradicionales, la oportunidad para debatir los planes de vida y la palabra del cacique, entre otros, como escenarios de empoderamiento de la comunidad. A través de estos espacios públicos las comunidades hacen visibles sus capacidades y necesidades ante instancias gubernamentales y no gubernamentales.

Debemos destacar que en los discursos de los jóvenes y de los niños se hace evidente un mayor interés en la modernización, entendida como un proceso que deriva de la presencia y uso de la tecnología instrumentalizada, así como en modelos de vida occidentales, que en preservar o fortalecer la propia cultura. En ese sentido, el reto para las nuevas generaciones de grupos indígenas suburbanos radica en plantearse a sí mismos modernidades propias, alternativas, que les permitan identificarse como lo que son, hacer uso de sus propios recursos y de su propia identidad para participar en igualdad de condiciones frente a los retos del siglo XXI.

Proponemos ejercicios de formación de líderes sin importar la edad, que desde el pasado y el presente de la comunidad den cuenta de los perfiles y formas de ejercicio de liderazgo más provechosos para el bien común, y que enfaticen en la figura del líder como la de alguien que se debe a su comunidad y que se encuentra al servicio de los demás, más que como alguien que se impone desde ejercicios de poder.

Otra experiencia que potencia el liderazgo tiene que ver con el uso de las tecnologías de la comunicación. Los ejercicios radiofónicos que realizamos en la Institución Educativa San Juan Bosco nos permitieron identificar la importancia de los medios como espacios para que las comunidades se reconozcan a sí mismas en sus lenguajes, sus narrativas, sus referentes identitarios fundamentales, así como en sus posibilidades de articular esfuerzos para su propio desarrollo. La sonoridad de sus relatos, su música, su lengua, su historia y su cotidianidad, unidas al entusiasmo de los jóvenes frente a la tecnología mediática y a las posibilidades de cobertura de la radio en la zona, ofrecen pistas para una segunda fase en donde las estrategias comunicativas se concentren en cómo hacer uso de un canal como la radio, hoy en día con una vocación comercial de espaldas a las necesidades culturales de la región. De esta manera, el medio radial puede convertirse en un escenario de encuentro, debate y diálogo, que permita visibilizar las diferencias y encontrar elementos comunes entre las comunidades, con miras a trascender los ejercicios difusionistas que han primado. Así contribuiríamos en la consolidación de espacios donde la tecnología esté al servicio de la comunicación y la cultura, y no al contrario, donde estas últimas deban subyugarse a la primera. 


\section{REFERENCIAS BIBLIOGRÁFICAS}

Acuña, C. (1891). Nuevo descubrimiento del gran río de las Amazonas. Madrid: Colección de libros que tratan de América, raros o curiosos, vol. 2.

Arango, R. \& Sánchez, E. (1999). Los pueblos indígenas de Colombia. 1997. Desarrollo y territorio. Bogotá: Tercer Mundo Ed.

Bayle, C. (1943). El Dorado fantasma. Madrid: Consejo de la Hispanidad.

Berganza Conde, M.R. \& San Román Ruiz, J.A. (2005). Investigar en Comunicación - guía práctica de métodos y técnicas de investigación social en comunicación. España.

Cendales G., L. (2000). El diálogo - recorrido y consideraciones a partir de la experiencia. El diálogo en la educación perspectivas teóricas y propuestas didácticas.Santafé de Bogotá: Dimensión educativa.

Carrillo Torres, A. (2003). Organizaciones populares, identidades colectivas y ciudadanía. Bogotá.

Entrevista a Marco Raúl Mejía por Lola Cedales G. (2000). Del intercambio de saberes a la negociación cultural. El dialogo en la educación - perspectivas teóricas y propuestas didácticas. Santafé de Bogotá: Dimensión educativa.

Ghiso, A. (2000). Potenciando la diversidad - Diálogo de saberes una práctica hermenéutica colectiva. El diálogo en la educación - perspectivas teóricas y propuestas didácticas. Santafé de Bogotá: Dimensión educativa.

Cassani, J. (1967). Historia de la Provincia de la Compañía de Jesús del Nuevo Reino de Granada en la América. Caracas: Fuentes para la Historia Colonial de Venezuela.
Coama. (1996). Derechos de los pueblos indígenas en las constituciones de América Latina. Bolivia - Brasil - Colombia - Ecuador Guatemala - México - Nicaragua - Panamá - Paraguay - Perú - Venezuela. Santafé de Bogotá: Disloque.

Codeba, (2004). Primer encuentro de autoridades tradicionales, líderes y profesionales indígenas del departamento de amazonas. Consultado el 23 de julio de 2009, en: http://www.codeba.org/index.ph $\mathrm{p}$ ? view $=$ article\&catid $=37 \% 3$ Aespacio$1 \& \mathrm{id}=44 \% 3$ Aencuentro-de-autoridades

Goldman, I. (1993). Hierarchy and power in the tropical forest. Configurations of power : holistic anthropology in theory and practice. J. Henderson y P. Netherly (eds.). Cornell University: Ithaca.

Goulard, J.P. (1998). Les genres du corps. Conceptions de la personne chez les Ticuna de la haute Amazonie. These doctoral. Ecole des Hautes Etudes en Sciences Sociales. Paris: Novembre.

Goulard, J.P.. (2000). La parole et le livre dans la configuration religieuse d'Amazonie. Chamanisme et messianisme chez les Ticuna. La politique des esprits. Denise Aigle, Bénédicte Brac de la Perrière et J-P Chaumeil (publié par). Nanterre: Société d'Ethnologie.

Goulard, J.P. (2002). Indios de la frontera, fronteras del indio. Una sociedad indígena entre tres Estados-naciones: los Ticuna. Lo transnacional. Instrumento y desafio para los pueblos indígenas. Morin, F y Santana, R. (comp.). Quito: Eds. Abya-Yala.

Hugh-Jones, S. (1995). Inside -out and backto-front: The androgynous house in 
northwest Amazonia. About the house: Lévy-Strauss and beyond. Janeth carsten y Stephen Hugh-Jones (eds.). Cambridge: Cambridge University Press.

Lasprilla López, V.A. (2009). Mujeres indígenas: significado y función del trabajo femenino en la comunidad indígena Ticuna. San Sebastián de Los Lagos. Tesis de grado Maestría en Estudios Amazónicos, Universidad Nacional de Colombia, sede Amazonia, Instituto Amazónico de Investigaciones - Imani.

Observatorio DESC Amazonía, Nodo Colombia. (2007). Situación de los derechos económicos sociales y culturales en la Amazonía colombiana. Bogotá, D.C., Colombia: ILSA.

Oyuela-Caycedo, A. \& Vieco Albarracín, J.J. (1998). La organización social de losTicuna del trapecio amazónico colombiano: una aproximación cuantitativa.. Revista Colombiana de Antropología, vol. 35.

Oliveira Pacheco Filho, de \&Souza Lima, A.C. de (1990). Massacre d'indians dans le Nord Amazonien. Les Tikuna et leur lutte par la terre. Ethnies, No. 11-12.

Pennano, G. (1994). La economía del caucho. Iquitos: CETA.

Roux, J.C. (1994). L'Amazonie Péruvienne. Un Eldorado dévoré par la forêt, 1821-1910. Paris: L'Harmattan.

Porro, A. (1996). O Povo das Aguas. Ensayos de etno-história amazónica. Petrópolis: Vozes.

Sistema de monitoreo de la protección de los derechos y la promoción del buen vivir de los pueblos indígenas de América Latina y el Caribe (s.f.). Definición de elementos de la matriz del sistema. Extraído el 29 de junio de 2009, en http:// www.fondoindigena.org/apc-aa-files/
documentos/monitoreo/Definiciones/ Definicion\%20Dominios/5_1_Planes\%20de\%20vida_def.pdf

UNESCO. (2002). Universal Declaration on Cultural Diversity. A document for the World Summit on Sustainable Development. Johannesburg 26 August-4 September. Paris: United Nations educational, Scientific and Cultural Organization.

Uruburu Gilède, S. (1996 - 1997). Manifestaciones mesiánicas entre los indígenas del río Guainía - río Negro. Revista Colombiana de Antropología, 33.

Vieco, J.J. (2007). El dilema del desarrollo en los pueblos indígenas del trapecio amazónico. Entre la distribución y la acumulación. Ponencia presentada al XII Congreso de Antropología en Colombia, Simposio Sociedades del Bosque Tropical. Bogotá.

Vieco, J.J. \& Uruburu, S. (2003). Diversidad cultural y desarrollo entre los Ticuna del trapecio amazónico. Trabajo presentado a la UNESCO, División de Políticas Culturales y Diálogo Intercultural. Paris.

Zárate Botía, C.G. (2008). Silvícolas, siringueros y agentes estatales. El surgimiento de una sociedad transfronteriza en la amazonia de Brasil, Perú y Colombia. 1880-1932. Bogotá: Ed. Universidad Nacional de Colombia.

\section{ENTREVISTAS Y RELATOS ORALES}

Abuelas San Sebastián de Los Lagos (2008, 29 de septiembre). Entrevista grupal realizada por Rodríguez, J. Leticia.

Alvear Peña, Nilson (2008, noviembre). Entrevista realizada por Rodríguez, J. y Cortés, D. Leticia. 
Cabildo de San Sebastián de Los Lagos (2008,11 de julio). Entrevista grupal realizada por grupos de investigación. San Sebastián de Los Lagos - Leticia.

Cauhache, Emperatriz (2008, noviembre). Entrevista realizada por Rodríguez, J. y Cortés, D. Leticia.

Fernández, Ángel (2008, 12 de septiembre). Entrevista realizada por Rodríguez, J. Leticia.

Lorenzo F., Ruth. (2008, 1 y 3 de octubre). Entrevista realizada por Rodríguez, J. San Sebastián de Los Lagos - Leticia.

Mandato Indígena (2008, septiembre 20). Lectura oral en cumbre de ancianos. Registro realizado por: Rodríguez, J. y Cortés, D. Puerto Nariño, Amazonas.
Matapí Yucuna, Walberto (2008, octubre). Entrevista realizada por: Rodríguez, J. Leticia.

Muinane, A. (2008, 19 de septiembre). Relato oral registrado por Rodríguez, J. y Cortés, D. Puerto Nariño, Amazonas.

Morales, Walter. (2008, 7 de julio). Entrevista realizada por: grupo de investigación. km 11 Leticia.

Sandoval, Miguel Ángel. (2008, octubre). Entrevista realizada por Rodríguez, J. km 11 Leticia. 